\title{
Mechanical Characterization of two blends PP+PA6+EPDM. Part 2. Results of Tensile Tests
}

\author{
George Ghiocel Ojoc ${ }^{1}$, Larisa Chiper Titire ${ }^{1}$, Ana Maria Musteață ${ }^{1}$, Mihail Boțann ${ }^{1,2}$, George Catalin Cristea ${ }^{1,2^{*}}$ and \\ Lorena Deleanu ${ }^{1, *}$ \\ 1 '"Dunarea de Jos University" of Galati, Romania; lorena.deleanu@ugal.ro, larisa.chiper@yahoo.com, \\ George.ojoc@ugal.ro \\ 2 National Institute of Aerospace Research “Elie Carafoli” - INCAS, Bucharest, Romania; cristea.george@in- \\ cas.ro \\ * Correspondence: C.G.C. cristea.george@incas.ro; L.D. lorena.deleanu@ugal.ro
}

\begin{abstract}
This paper presents the values of several mechanical characteristics for two blends: $\mathrm{H}(60 \%$ $\mathrm{PP}+12 \% \mathrm{PA} 6+8 \% \mathrm{EPDM}+20 \%$ Polybond 3200$)$ and G $(20 \% \mathrm{PP}+42 \% \mathrm{PA} 6+28 \% \mathrm{EPDM}+10 \%$ Polybond 3200) (\%wt), comparing them to those of PP (polypropylene) and PA6 (polyamide 6). The adding of EPDM (ethylene propylene diene monomer rubber) and Polybond 3200 help reducing the disadvantages of simple blends made of PP+PA6, when the PA6 concentration allows for having a PA6 matrix with droplets of PP. SEM analysis helps for understanding the performance of material $\mathrm{G}$ as compared to the neat polymers. EDX analysis proved that there was a matrix inversion, material $\mathrm{H}$ having a PP matrix and material G a matrix made of PA6 with droplets of PP. Strain at break for PP and material $\mathrm{H}$ were proved to be insensitive to test speed, but materials $\mathrm{G}$ and PA6 had large value for strain at break and energy at break for $\mathrm{v}=10 \mathrm{~mm} / \mathrm{min}$. Taking at basis the values for polyamide 6 (PA6), material G has greater values for energy at break: with $97.8 \%$ for $\mathrm{v}=10 \mathrm{~mm} / \mathrm{min}$, with $29.5 \%$ for $v=250 \mathrm{~mm} / \mathrm{min}$ and with $98 \%$ for $1000 \mathrm{~mm} / \mathrm{min}$, without exhibiting the micro and macro cavitation of PA6. This means that the recipe, the technology and the mechanical characteristics make material $\mathrm{G}$ a potential candidate for applications where a low and moderate impact resistant material is required.
\end{abstract}

Keywords: polyamide 6, polypropylene, blend, EPDM, mechanical characteristic, energy at break

\section{Introduction}

The polymer blend segment is growing three times faster than the entire plastics industry. Polymer blending is the most suitable method to produce materials that meet requirements of the market. The aspiration is to produce a blend that can be treated like any other polymer; therefore, the processing of the blend must be consistent with that of simple polymers, but with better performance [1]. The main objectives of polymer blending are [2]:

- improving processing and productivity efficiency,

- producing materials with better mechanical performance, lighter parts,

- mixing of scrap reduction,

- mixing reduces the number of assortments to be stored and manufactured.

The method of compatibilizing immiscible polymers (like PP + PA) may include several alternatives [2-6]: the addition of a coating-type copolymer, also called impact modifier because it improves impact qualities, the addition of the third component to the polymer blend, miscible with both polymers, the addition of a reactive element that develops a local miscibility, additives having mechanical and/or chemical influence in the blend, etc.

\section{Blends based on PP and PA6}

DSM, Atochem and Mitsubishi introduced PA + PP blends due to their lower water absorption than polyamides, dimensional stability (affected by PP concentration), low 
density, low permeability of liquids and vapors and moderate impact strength, induced by PA and good resistance to alcohols [7].

PP (polypropylene) is a cheap general-purpose polymer, with high purity and chemical stability, but low impact resistance [8]. It has a crystallinity degree of $50-60 \%$ [9]. The set of properties includes low density, high melting point $\left(\mathrm{T}_{\mathrm{m}}=166^{\circ} \mathrm{C}\right)$ and good processability. The low temperature impact resistance of unmodified PP and the Izod impact resistance give lower values than those obtained for PE. Fragility is related to spherulitic morphology and the tendency of cracking by spinning PP, which increases in the presence of stress concentrators, especially at negative temperatures [4], [10]. PP has a high wear resistance, does not crack in corrosive environments and it is resistant to ultraviolet rays and oxygen. When stabilizers are added, this performance is improved. When PP is in contact with organic solvents, only a slight swelling occurs. One of the main problems faced by PP components is the low impact resistance. It follows that the blend of PP with other polymers and/or elastomers would improve this property, while maintaining to some extent the qualities of the polymer [11]. The softening of PP begins at $140{ }^{\circ} \mathrm{C}$, the melting temperature being in the range from $164{ }^{\circ} \mathrm{C}$ to $170{ }^{\circ} \mathrm{C}$, and from $-8{ }^{\circ} \mathrm{C}$ down the polymer becomes brittle. Trademarks usually contain antioxidant stabilizers and other additives [12].

All types of polyamides (PA6; PA6.6; PA6.10; PA6.12; PA11, PA12) have many applications because they can be processed much easier as compared to other polymers, have good wear resistance and high melting temperatures, but, as a disadvantage, they have a relatively high cost and absorb water very easily [13].

There are three methods to achieve PP-PA compatibility: physical compatibility by high stress field in processing, heat treatment, irradiation, etc. chemical compatibilization, by incorporating a compatibilizing agent, usually either a copolymer or multipolymer and reactive compatibility during processing by extrusion or injection molding [14], [15].

Blends PP and PA6 have been tested for improving mechanical properties, where PP ensures good processability and moisture insensitivity, while PA6 contributes with mechanical and thermal properties. Researchers have described nanocomposites based on unique polymer matrix [16], [17]. A new approach is represented by composites based on polymer blends of two or more polymeric materials. Nanocomposites based on PA6/PP blends have been analyzed [5]. Blends PP+PA have immiscible components, usually with highly asymmetrical compositions (90/10, 80/20 or 70/30), insular morphologies, with large droplets and a lack of adhesion between phases, as a result of high values of interfacial tensions between immiscible phases [18], [19]. A simple FE model [20] pointed out that a bonded droplet behaves very different as concern the stress and strain distributions, when comparing to a matrix that could slide along the dispersed phases. Immiscible blends have poor mechanical properties if no compatibilizing agents are added. In the recent decades, positive results have been reported for these blends, but with different compatibility agents [21-26].

For PP + PA blends, the researchers investigated the influence of adding elastomers: styrene-ethylene-butylene-styrene maleate (SEBS) [27-29], ethylene-polypropylene-diene copolymer (EPDM) [26], [30-34]; acryl-butadiene-styrene elastomer (ABS), copolymer block styrene-ethylene-butylene-styrene maleat (SEBS) [21],] [35].

Impact resistance is usually improved to the detriment of strength and dimensional stability. The rigidity of polyamides with the addition of elastomer can be preserved to some extent by inorganic additions (glass micro spheres [36], short glass fibers [37], minerals and clays [37], carbon nanotubes [38], [39] and organic (short aramid fibers [40]). Chow et al. [19] and Wahit et al. [41] also reported that the ductility and resilience of PA6 $+\mathrm{PP}+$ clay blends were improved by the addition of an elastomer.

EPDM was used as a compatibilizer in PP/LDPE blends and their mechanical properties and Izod impact resistance improved due to its addition, especially for LDPE-rich ones and those with a high EPDM content. The compatibilizer did not have an effect of improving the tensile strength, except for the PP/LDPE blend (80/20). Interfacial adhesion was also improved [42]. 
Here are some examples of elastomers added to PA and PA + PP blends: PA6/maleated methylene diylene ethylene propylene monomer (mEPDM)/nanoclay [43], PA6/metallocene ethylene-propylene-diene terpolymer (EPDM)/sepiolite [44]; PA6/ ethylene propylene propylene diene methylene (EPDM-g-MA)/organic clay [45], PA6/ ethylene-polypropylene-diene copolymer metallocene + ethylene-polypropylene- diene copolymer/ethylene-polypropylene-diene copolymer maleate (EPDM-g-MA) + clay [46].

In polymeric blends, cavitation occurs at micro and/or macro levels. The cavities are generated in the blend volume, either during cooling after injection of the melt into the mold or due to stresses induced under load [21], [47], [48].

Bai et al. [22] developed a class of blends, composed of three phases: PP, PA6 and polyethylene-octene elastomer (POE), crosslinked with maleic anhydride. The mass fraction of PA6 was adjusted from $0 \%$ to $40 \%$, in steps of $10 \%$, and the mass fraction POE was kept at half that of PA6. Their morphology was mainly from PA6 particles dispersed in the PP matrix. The POE modifier was observed as a thin interface (less than $100 \mathrm{~nm}$ thick) at the PP/PA6 interface, and as isolated, but few, particles. The modulus of elasticity and the tensile strength at break are almost constant for PP and elaborated blends, but Izod impact resistance increases greatly with the content of the alloying components. This effect is due to POE reducing the interface cavitation, to higher resistance of PA6 drops to crack propagation and to the larger plastic deformation.

$\mathrm{PA}+\mathrm{PP}$ blends were considered interesting materials because both components are relatively cheap, with advantageous properties and can be processed by melt mixing. The compatibility of polymers in blends can be achieved by the addition of reticulating copolymer, segments that have physical or chemical affinity with immiscible homopolymers. In this study, the authors used PP reticulated with maleic anhydride (PP-g-MA). Graphite and graphene oxide were added in the blends. The family of blends had the objective of railway components (seals) that simultaneously meet impact strength, wear durability on temperature range $-40^{\circ} \ldots+240^{\circ} \mathrm{C}$, in difficult weather conditions [49].

To reduce the sensitivity of polyamide to crack initiation and its development on low velocity impact, the polymer is mixed with 10-25\% elastomer (including EDPM that was used for these two original recipes) [50].

The mechanical properties, phase morphology and breaking behavior of the ternary blends PP/PA6/(EPDM:EPDM-g-MA) (70/15/15), with different concentrations of EPDM:EPDM-g-MA, were presented in a recent study [32]. With the addition of EPDMg-MA, the strain at break increases. PP has a semi-ductile behavior in tensile tests and PA6 has a ductile fracture as compared to PP, with a higher tensile strain and higher tensile strength.

\section{Materials and Methods}

The properties of polymer blends depend on their morphology, the quality of the interfacial adhesion, the surface tension and the package of properties with which each component contributes [51-55]. As in the case of PA + PP blends, a polymer blend may have in its composition several stabilizing agents and nanoparticles that can improve the interfacial adhesion and morphological stability of immiscible polymer blends [25].

PA6 brings in a blend its mechanical and thermal properties and PP brings processability, water insensitivity and dimensional stability [21], [23], [25].

Polybond 3200 as a miscibility agent is a chemically modified polypropylene. Physical properties of blends could be modified by using lower levels of addition; it is a chemical coupling agent for glass fibers and PP-reinforced mineral filler, which improves the physical and thermal properties; it is a compatibilizer for polypropylene/polyamide and polypropylene blends for improving processing and mechanical properties.

Chow et al. [19] used MAH-g-PP (Polybond 3200), having $1.2 \mathrm{wt} \%$ maleic anhydride (MA). Tensile tests were performed at a test rate of $50 \mathrm{~mm} / \mathrm{min}$. The modulus of elasticity was less sensitive to the addition of MAH-g-PP in blends with PA6, but considerably increased the toughness of a composite, largely due to clay reinforcement. 
EPDM (ethylene-propylene-diene maleate monomer) is a synthetic rubber monolayer membrane, sometimes mixed with carbon black, oils, curing agents and other additives, chemically stable, resistant to ultraviolet rays and ozone, practically unlimited. Elongation of over $300 \%$ gives EPDM the advantage of withstanding mechanical stress that other materials cannot. At $-40{ }^{\circ} \mathrm{C}$, EPDM keeps its properties, while thermoplastics lose their elasticity and become hard and brittle and at $+150^{\circ} \mathrm{C}$, EPDM also keeps its properties, while thermoplastics liquefy. After repeated stretching, EPDM retains its properties, while thermoplastics become thin, elongated or breaks [56].

The recipes of the blends were established by agreement with the Monofil SA Săvinești (Romania), which also made the specimens by mold injection. The two polymeric blends consist of four elements, namely: PA6, PP, EPDM and Polybond 3200, in the concentrations shown in Table 1.

Table 1. Concentrations of the blends [wt $\%]$

\begin{tabular}{ccccc}
\hline Material & PA6 & PP & EPDM & Polybond 3200 \\
\hline PP & - & 100 & - & - \\
H & 12 & 60 & 8 & 20 \\
G & 42 & 20 & 28 & 10 \\
PA6 & 100 & - & - & - \\
\hline
\end{tabular}

Figure 1a schematically shows the laboratory technology for obtaining the materials developed by the authors, with the involvement of the company Monofil SA Săvinești, Figure $1 \mathrm{~b}$ presenting the injection molding equipment.

The technological flow consists of the pre-mixing of granules of PA6, PP and Polybond 3200 in a mixer (high speed mixer), with a capacity of 2001 , mixing speed 475/950 rpm, equipped with a heating system with electrical resistances of $11 \mathrm{~kW}$ and pneumatic discharge system. It is essential to pre-mix the components in a mixer, before introducing them into the extruder, because the raw materials have different densities. This methodology will guarantee a uniform dispersion of the components in the mass of molten polymer and, implicitly, an extremely low degree of agglomeration [26].

Blends of polymers and additives, resulting from the high-speed mixer, will be introduced at a temperature of $80-100{ }^{\circ} \mathrm{C}$ in a drying hopper. The dryer is equipped with an automatic system for loading and unloading, with a capacity of $1500 \mathrm{l}$ and a working flow of $200 \mathrm{~kg} / \mathrm{h}$. The pre-mixtures in the drying hopper are automatically loaded into the primary dosing system. The primary dispenser has the following technical data: dosing flow $=150 \mathrm{~kg} / \mathrm{h}$, dosing speed = maximum $100 \mathrm{rpm}$, dosing system with double screw; feed hopper volume $=150 \mathrm{l}$.

The compounding of polymer and additives was performed on a granulating extruder type EC 52, with double screw (diameter $51.4 \mathrm{~mm}$ ), with simultaneous rotation, injection pressure being 60 bar. The extruder is equipped with a cooling system of the zones using softened water jacket, respectively a hydraulic system for continuous filtration of the melt, equipped with a $1.5 \mathrm{~kW}$ motor and a maximum working pressure of 20 MPa [26]. The injection molding parameters are given in Table 2. 


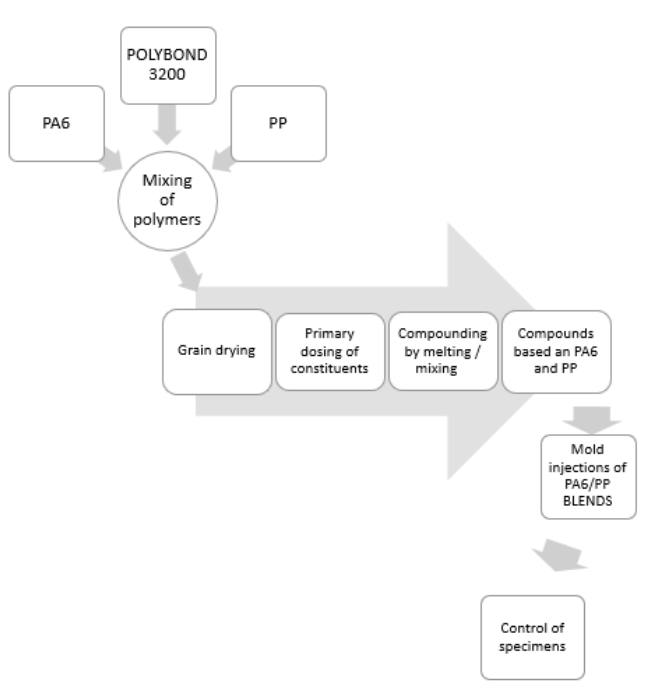

(a) Flow chart of the laboratory technology

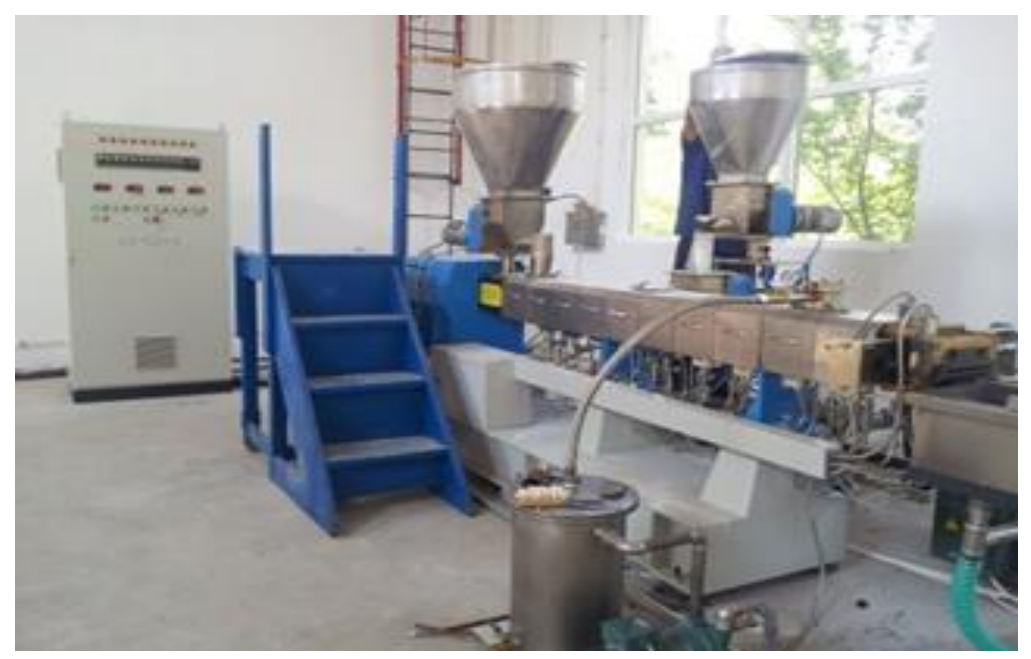

(b) Granulating extruder with double screw type EC 52 (SC Monofil Săvinești SA, Romania)

Figure 1. Technological flow chart for obtaining the specimens made of PA6, PP and the two blends

Table 2. Optimal compound processing parameters.

\begin{tabular}{|c|c|c|c|}
\hline No. & Technological parameters & UM & Values \\
\hline 1 & $\begin{array}{l}\text { working temperature on the } 3 \text { zones (from } 9 \\
\text { available on the equipment): } \\
\text { Zone I } \\
\text { Zone V } \\
\text { Zone IX - }\end{array}$ & ${ }^{\circ} \mathrm{C}$ & $\begin{array}{l}130-150 \\
240-260 \\
220-230\end{array}$ \\
\hline 2 & Screw diameter & $\mathrm{mm}$ & 51.4 \\
\hline 3 & Ratio L/D & & $40: 1$ \\
\hline 4 & Maximum rotary screw speed & $\mathrm{rpm}$ & 600 \\
\hline 5 & $\begin{array}{l}\text { Modular screw structure, with } 5 \text { types of sec- } \\
\text { tions of different lengths }\end{array}$ & $\mathrm{mm}$ & $16-48$ \\
\hline 6 & Axial pressure & $\mathrm{kN}$ & $4.5-5.5$ \\
\hline 7 & Melt pressure & bar & $50-60$ \\
\hline 8 & Melt temperature & ${ }^{\circ} \mathrm{C}$ & $90-100$ \\
\hline 9 & Supply current intensity & $\mathrm{A}$ & 24 \\
\hline 10 & Main engine power & $\mathrm{kW}$ & 55 \\
\hline
\end{tabular}

\section{Tensile test results}

For each material, 5 tests were performed (according to the standard SR EN ISO 5272: 2012) for each material and each test speed, namely $10 \mathrm{~mm} / \mathrm{min}, 250 \mathrm{~mm} / \mathrm{min}$ and 1000 $\mathrm{mm} / \mathrm{min}$. The following parameters were analyzed: modulus of elasticity, tensile strength at break, strain at break, energy at break. Each characteristic was represented by the average values, the maximum and minimum values, as obtained from engineering stressstrain curves.

Following the use of INSTRON 2736-004 tensile test machine (INCAS, Bucharest) and its dedicated software, the true stress-strain graphs were represented in Figures 2.

According to the literature, the strain rate, $\dot{\varepsilon}$ can be defined approximately by the relation (1) and the values obtained are given in Table 3.1:

$$
\dot{\varepsilon}=\frac{v}{L_{0}}\left[s^{-1}\right]
$$

where $\mathrm{v}$ is the test rate, in $\mathrm{mm} / \mathrm{s}$ and $\mathrm{L}_{0}$ is the length of constant cross section, supposed to be deformed during the tensile test.

Table 3. Values of the strain rate 


\begin{tabular}{cccc}
\hline $\mathbf{v}$ & $\mathbf{v}$ & $\mathbf{L}_{0}$ & $\dot{\boldsymbol{\varepsilon}}=\frac{\boldsymbol{v}}{\boldsymbol{L}_{\mathbf{0}}}\left[\boldsymbol{s}^{\mathbf{- 1}}\right]$ \\
\hline $\mathbf{m m} / \mathbf{m i n}]$ & {$[\mathrm{m} / \mathbf{s}]$} & {$[\mathrm{mm}]$} & $3.32 \times 10^{-3}$ \\
10 & 0.000166 & & $83.2 \times 10^{-3}$ \\
250 & 0.00416 & 50 & $332 \times 10^{-3}$ \\
\hline
\end{tabular}

Figure 2 presents the true stress-strain curves for the analyzed materials for all 5 tested spec imens, till their break. The true stress and the true strain were calculated with the help of the following relations

true tensile stress

$$
\sigma=\mathrm{F} / \mathrm{A}
$$

tensile stress at traction (engineering)

$$
\sigma_{\text {eng }}=\mathrm{F} / \mathrm{A}_{0}
$$

strain rate in traction (engineering)

$$
\varepsilon_{\text {eng }}=\Delta \mathrm{L} / \mathrm{L}_{0}
$$

where $\mathrm{F}$ is the force applied at time $\mathrm{t}, \mathrm{A}$ - cross area of the specimen at time $\mathrm{t}, \mathrm{A}_{0}$ - initial cross area of the specimen (as measured), $\mathrm{L}_{0}$ - initial length of specimen between marks, $\mathrm{L}$ - the length between marks, at moment $t$.

If the engineering values are known, the relations used in this paper to calculate the true values are:

- true strain

$$
\varepsilon_{\text {true }}=\ln \left(1+\varepsilon_{\text {eng }}\right)
$$

- true tensile stress in traction

$$
\sigma_{\text {true }}=\sigma_{-} \text {eng }\left(1+\varepsilon_{\text {true }}\right)
$$

The material PP (Fig. 2, first line), by its tendency of overlapping curves, can be considered a fairly predictable polymer, except for the strain at break, which varies quite a lot at the lowest test speed and much less at higher test speeds. The slower the load is applied to the test piece, the bigger the strain at break as compared to the strain at higher test speeds, where the strain at break is small in value. Strapasson et al. [57] performed tests at $5 \mathrm{~mm} / \mathrm{min}$ and the results of mechanical characteristics for PP, injected at $170{ }^{\circ} \mathrm{C}$, $180{ }^{\circ} \mathrm{C}, 190^{\circ} \mathrm{C}$ and $200{ }^{\circ} \mathrm{C}$, show the importance of the injection temperature: strain at break at $190{ }^{\circ} \mathrm{C}$, decreases from $650 \%$ to $10 \%$, indicating severe degradation. The stressstrain curves after sample injection at $170{ }^{\circ} \mathrm{C}$ are approximate to those obtained by the author for $10 \mathrm{~mm} / \mathrm{min}$, the range of strain at beark values is smaller than that obtained at $5 \mathrm{~mm} / \mathrm{min}$ (as it is normal), but the values of the elasticity modulus are close.

In material $\mathrm{H}$ (Fig. 2, second line), the lowest concentration of polyamide is found, namely $12 \%$ PA6. There is a tendency to maintain the shape of the stress-strain curves in the elastic zone, up to about 20-25 MPa, after which the curves are spread in the plastic domain, over a range of about $25 \mathrm{MPa}, 40 \mathrm{MPa}$, respectively. One can note the break occurred at very different values of strain. Therefore, the material has a predictability on which the design engineer can rely only in the range of $0-20 \mathrm{MPa}$, after this value, the break takes place in a wide range of stress, from $25 \mathrm{MPa}$ to $40 \mathrm{MPa}$. If parts made of this material are designed, it should not exceed 15-20 MPa, in the maximum values, in order to remain in the elastic zone. Thus, from the tests performed for material $\mathrm{H}$, it is found the unpredictable behavior of this material after stress values of $25 \mathrm{MPa}$.

Material G has a concentration of $42 \% w t$ PA6 and the scattering of the results obtained for strain at break falls within quite wide ranges (Fig. 2, third line). It is possible to observe the overlap of the true stress-strain curves in the elastic domain and the 


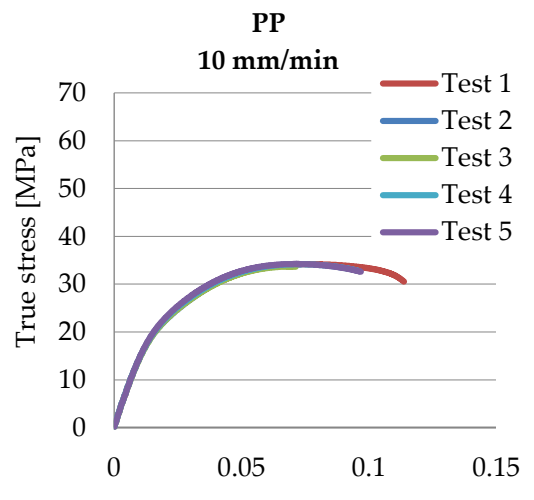

True strain [-]

H

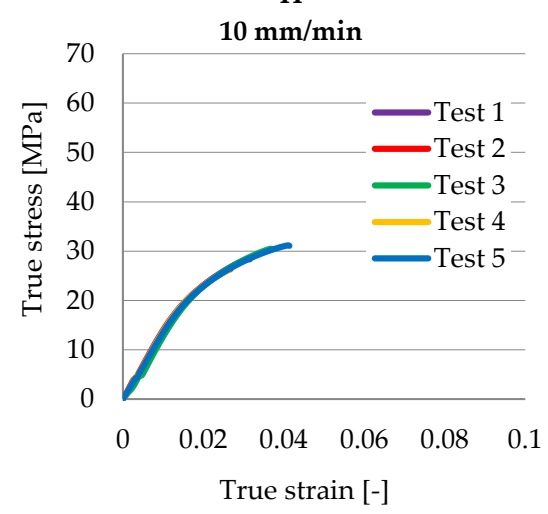

G

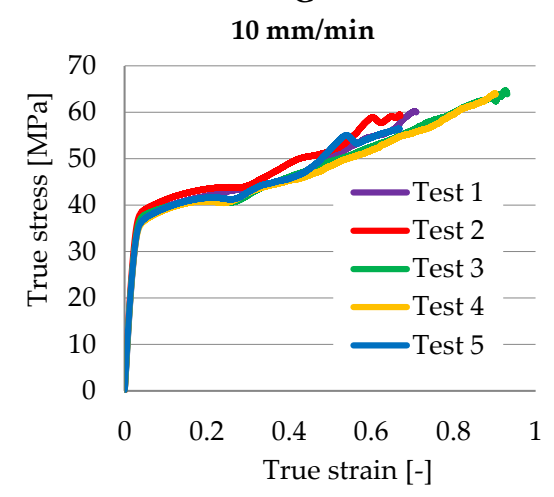

PA6

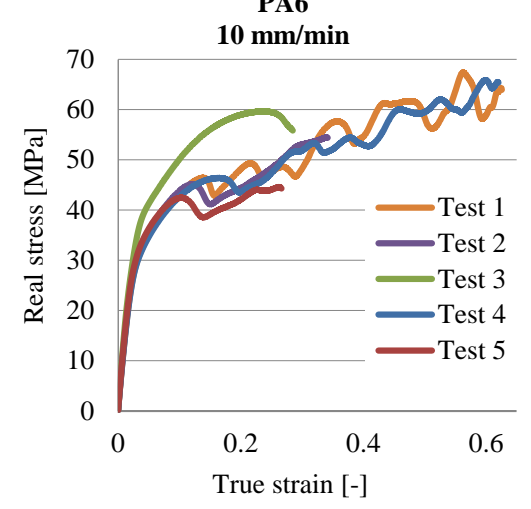

(a)

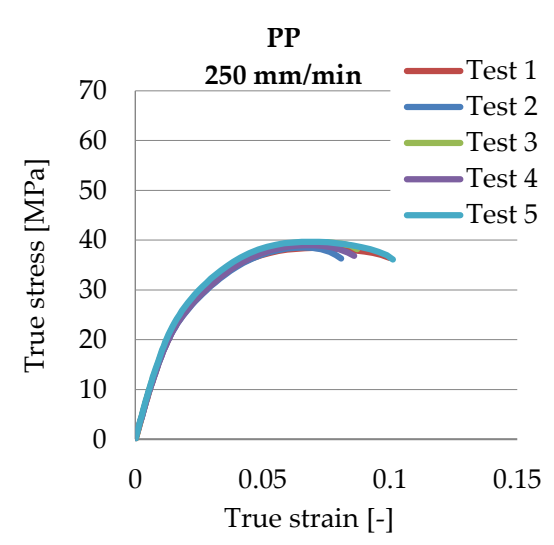

$\mathbf{H}$

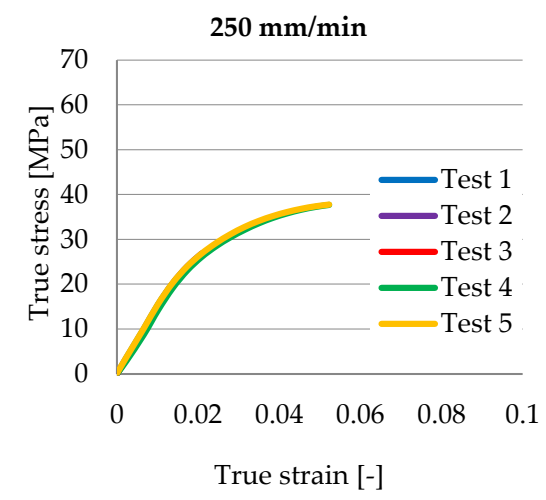

G

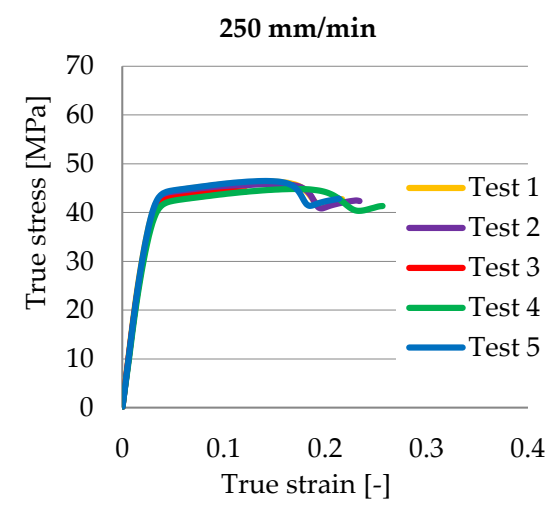

PA6

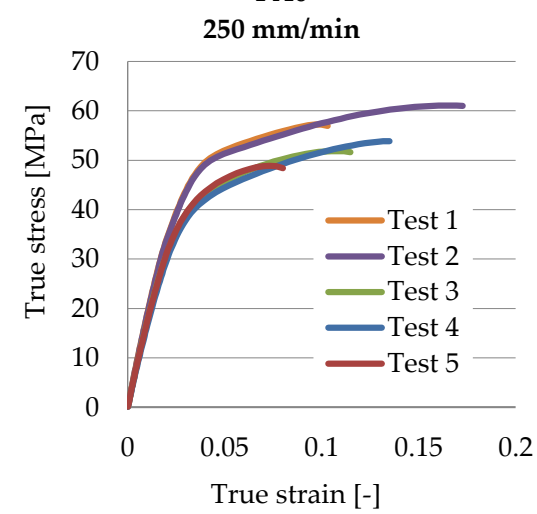

(b)

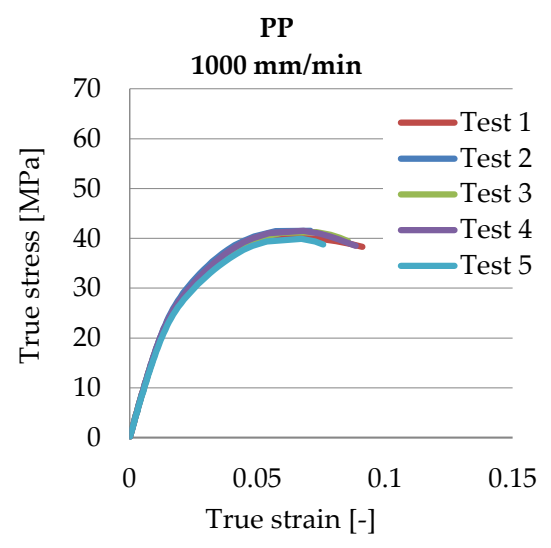

$\mathbf{H}$

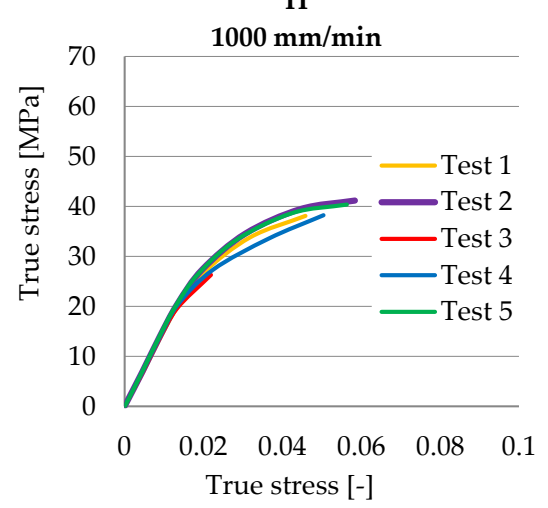

G

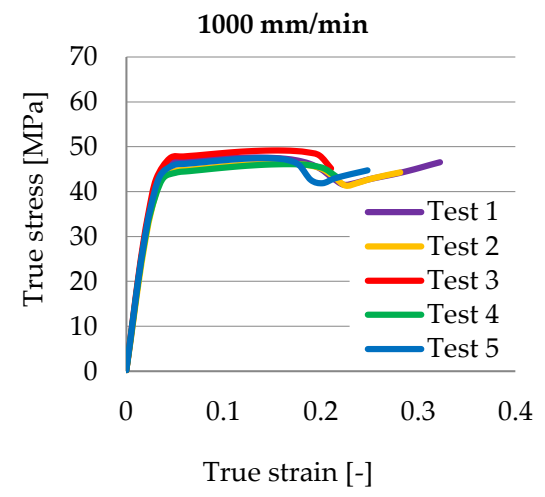

PA6

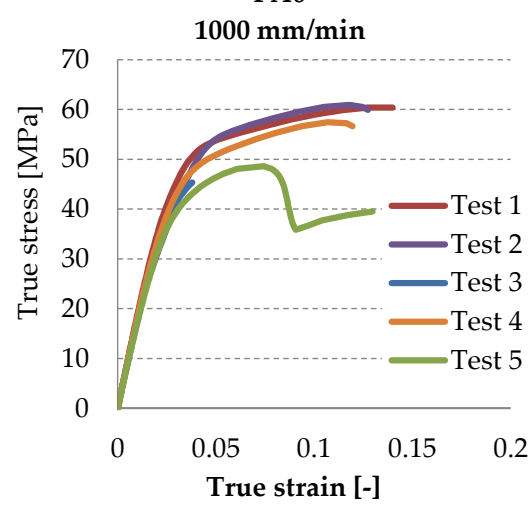

(c)

Figure 2. True stress-strain curves for:(a) PP and (b) PA6, for three test rates (10 mm/min, $250 \mathrm{~mm} / \mathrm{min}$ and $1000 \mathrm{~mm} / \mathrm{min})$

nonlinear elasto-plastic zone, then a slight distance appears in the area of plastic flow. On all curves, two domains can be observed, except for those obtained at speed $\mathrm{v}=10$ $\mathrm{mm} / \mathrm{min}$, where three domains appear, namely the first domain in the elastic zone (almost 
linear slope where the upper value and inclination are slightly sensitive to the stress speed, then a zone with a yielding plateau (plastic deformation visibly more pronounced for lower test speeds, ie $\mathrm{v}=10 \mathrm{~mm} / \mathrm{min}$ ), and finally the zone with a steeper slope. The very close behavior of the parts on demand is highly sought after by design engineers, being a defining selection criterion. For test speeds $250-1000 \mathrm{~mm} / \mathrm{min}$, the shape and characteristics of the curves are quite similar and the values of stress at break show a slight upward trend (see Fig. 5).

Figures 3 and 4 present the sets of 5 specimens tested for each material, for the selected three test speeds. Local neckings appear on the PA6 material (Fig. 3d, e and f), but not on the PP (Fig. 3a, b and c). At speed v $=10 \mathrm{~mm} / \mathrm{min}$, PP has an almost transverse breaking surface, with the exception of one of the 5 specimens with breaking fibers and a slightly pronounced neck.

In Fig. 3d (last line), from the set of 5 tested specimens made of PA6 material, at speed $\mathrm{v}=10 \mathrm{~mm} / \mathrm{min}$, two specimens have a continuous flow over a longer interval until breaking, and the other three have a shorter one. The shape of the stress-strain curves up to rupture, for the other test speeds, also consists of two regions: the first almost linear, in the elastic zone framed in a narrow value band, up to about $30 \mathrm{MPa}$ at $\mathrm{v}=10 \mathrm{~mm} / \mathrm{min}$, and $35 \ldots 40 \mathrm{MPa}$ for the other speeds. In the second region appears the area of the elastoplastic curves that connect with the flow bearings. The yield level at $\mathrm{v}=10 \mathrm{~mm} / \mathrm{min}$ has ripples, which means that the material is a polymer formed of crystalline and amorphous micro-volumes where large local flows are highlighted.

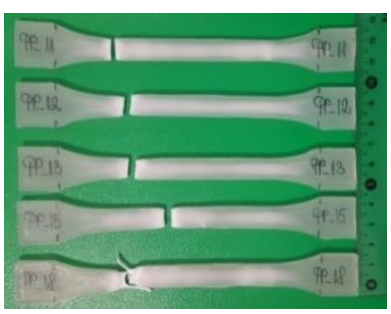

(a)

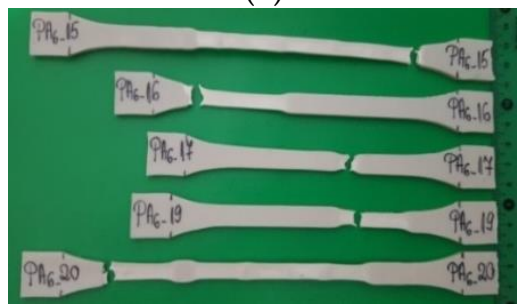

(d)

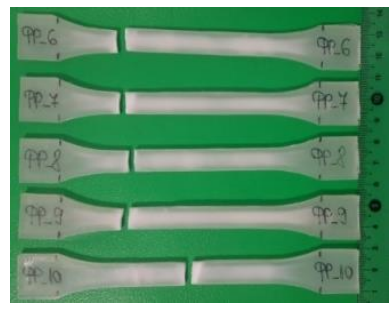

(b)

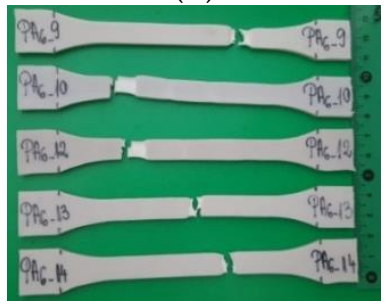

(e)

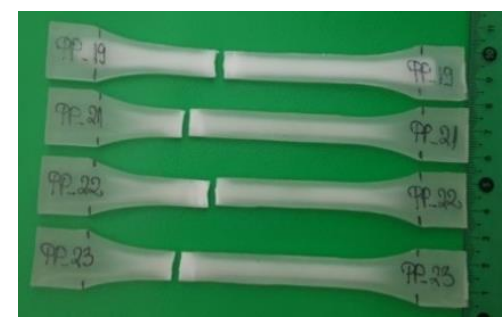

(c)

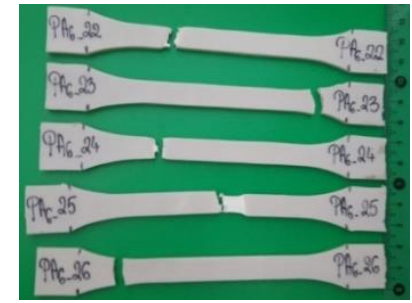

(f)

Figure 3. Samples made of PP after been tested in traction: (a) $10 \mathrm{~mm} / \mathrm{min}$; (b) $250 \mathrm{~mm} / \mathrm{min}$; (c) $1000 \mathrm{~mm} / \mathrm{min}$ and samples made of PA6 after been tested in traction: (d) $10 \mathrm{~mm} / \mathrm{min}$; (e) $250 \mathrm{~mm} / \mathrm{min}$; (f) $1000 \mathrm{~mm} / \mathrm{min}$.

Specimens made of material H (Fig. $4 \mathrm{a}, \mathrm{b}$ and c) present brittle fracture, the aspect being similar to $\mathrm{PP}$, this being explicable as the matrix of the blend $\mathrm{H}$ is made of PP.

In material G (Fig. 4d), at the test speed $\mathrm{v}=10 \mathrm{~mm} / \mathrm{min}$ there are bottlenecks on the test specimens and large elongations until breaking, this being characteristic of ductile materials and this makes the values of the tensile breaking energy have high values. However, the appearance of local necks can also be observed at the other test speeds, which may mean changes in the morphology and/or crystallinity of the polymer, possibly due to the force of stress. 


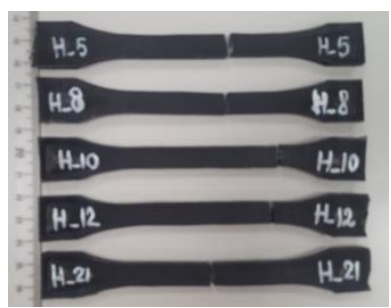

(a)

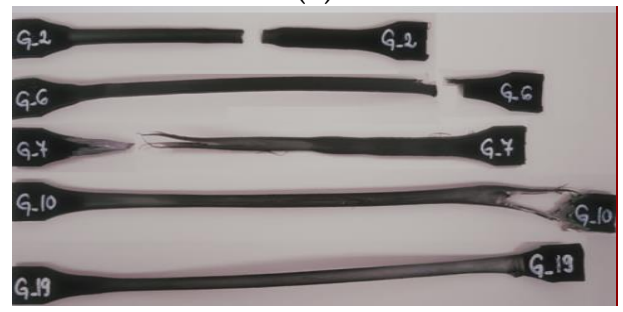

(d)

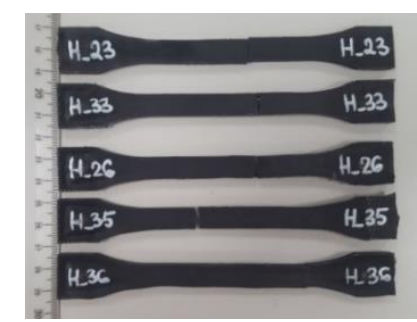

(b)

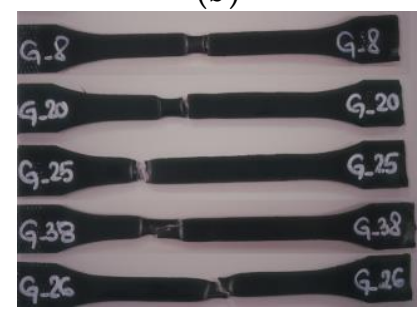

(e)

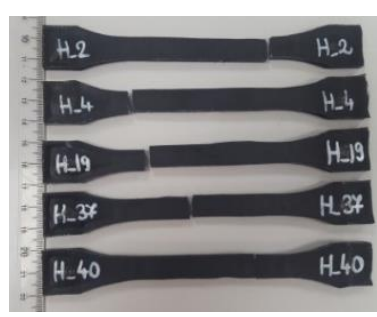

(c)

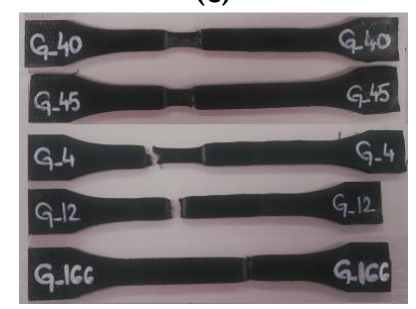

(f)

Figure 4. Samples made of material $\mathrm{H}$ after been tested in traction: (a) $10 \mathrm{~mm} / \mathrm{min}$; (b) $250 \mathrm{~mm} / \mathrm{min}$; (c) $1000 \mathrm{~mm} / \mathrm{min}$ and samples made of material G after been tested in traction: (d) $10 \mathrm{~mm} / \mathrm{min}$; (e) $250 \mathrm{~mm} / \mathrm{min}$; (f) $1000 \mathrm{~mm} / \mathrm{min}$

Average values of mechanical characteristics and their spread intervals for each tested material are given in Fig. 5.

For PP (Fig. 5, first column), the mechanical properties have a low ssensitivity to the test speed and the spread intervals are small. The average strain at break for the other two test speeds varies between $8.6 \%$ and $9.9 \%$ as comparing to the average values. The values obtained for the strength at break fall within a narrow range, so the highest tensile test speed $(1000 \mathrm{~mm} / \mathrm{min})$ causes the values for strength at break to increase with $59.14 \%$ for $\mathrm{PP}$ as compared to the value for $\mathrm{v}=10 \mathrm{~mm} / \mathrm{min}$. In the case of the strain at break, the values are slightly sensitive to the test speed, the samples made of PP broke at a strain of $9 . . .13 \%$. The graphs of energy at break and strain at break follow the same trend, namely, the values of the parameters decrease with increasing test speed, as reported in other research [23]. The modulus of elasticity is slightly influenced by the test speed and the obtained values increase with the increase of the latter, so that the lowest value for this parameter $(1623 \mathrm{MPa})$ was obtained at the lowest test speed $(10 \mathrm{~mm} / \mathrm{min})$, and for the other two speeds, the values increased by about $13 \%$ and $10 \%$, respectively.

Material $\mathrm{H}$ (with a content of $12 \%$ PA6, Fig. 5, second column) presents the following conclusions regarding the influence of the test speed on the mechanical parameters:

- the modulus of elasticity seems to be less sensitive to the test speed, the increasing values over the test speed range being only $3.8 \%$ as compared to value at the lowest test speed,

- the strength at break is clearly dependent on test speed, slightly increasing, almost linear, with a small slope,

- the average values, as well as the maximum strain at break are between about $3.3 \%$ and $4.8 \%$, therefore the dependence on the test speed is low, but the spread intervals are quite large,

- the values of the energy at break increase linearly with increasing test speed, so that the lowest value was obtained for $\mathrm{v}=10 \mathrm{~mm} / \mathrm{min}(2,6 \mathrm{~J})$, after which the values increased by $35 \%$ for $250 \mathrm{~mm} / \mathrm{min}$ and by $107,7 \%$ at the highest test speed $(1000 \mathrm{~mm} / \mathrm{min})$, while maintaining values lower than those obtained for PP; this is an atypical behavior.

For material $\mathrm{H}$, the average values of the four discussed parameters (strength at break, strain at break, modulus of elasticity and energy at break) show an increasing trend with the test speed (from $10 \mathrm{~mm} / \mathrm{min}$ to $1000 \mathrm{~mm} / \mathrm{min}$ ) and, yet the values are lower than those of simple polypropylene. 

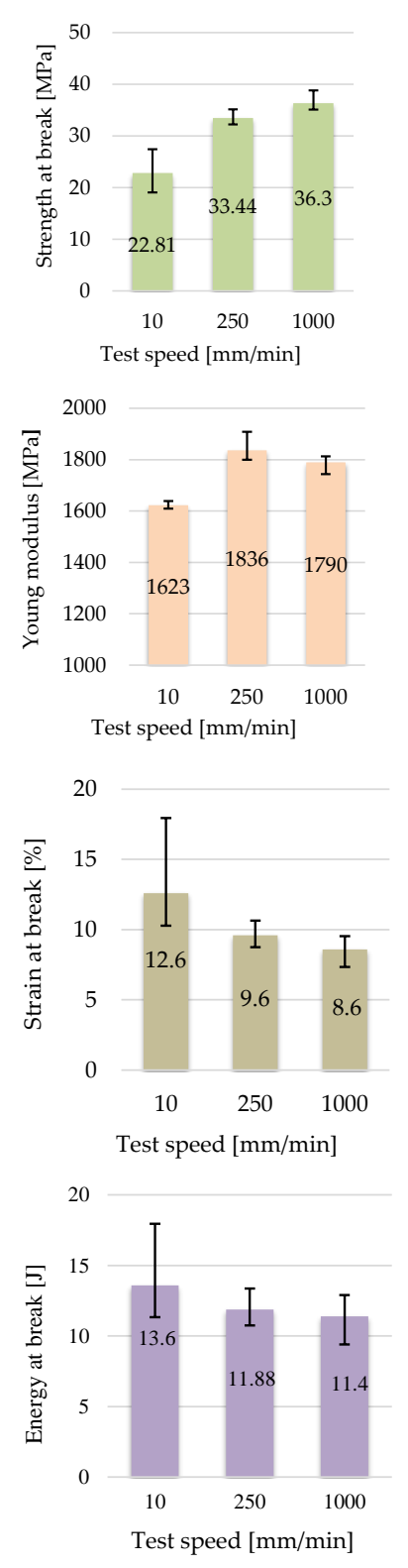
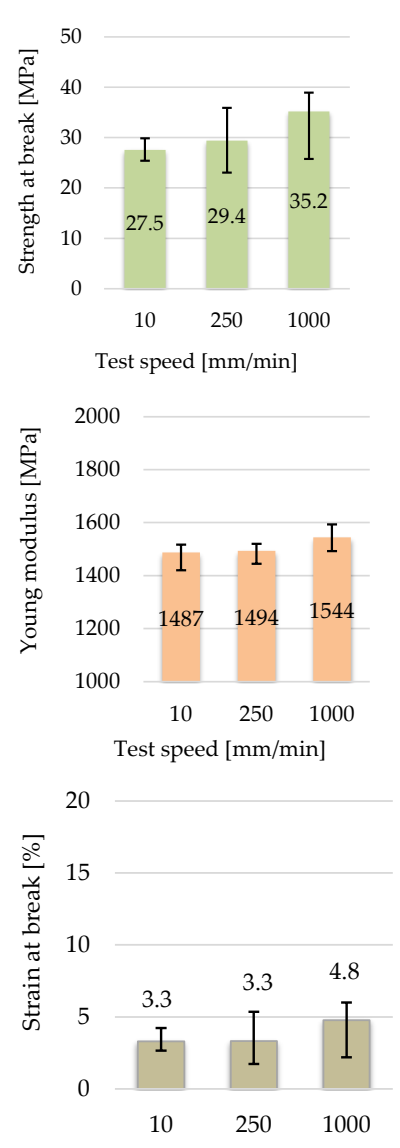

Test speed $[\mathrm{mm} / \mathrm{min}]$

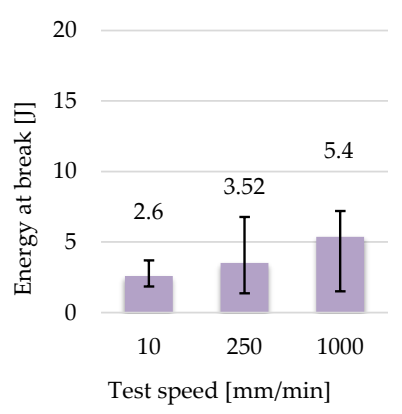

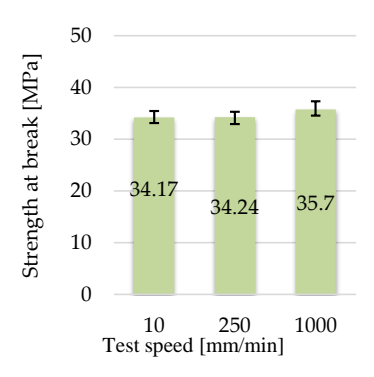
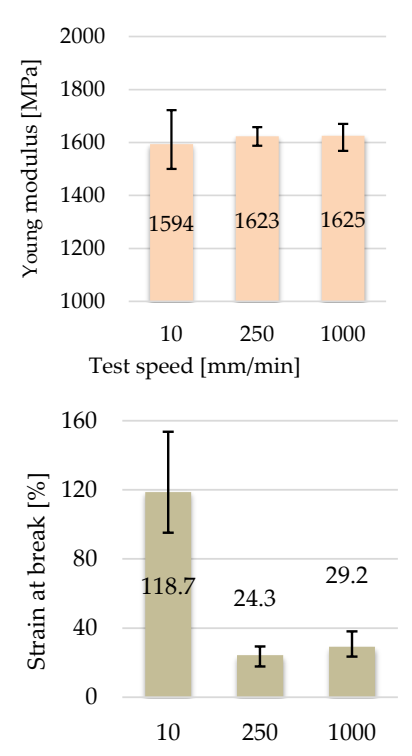

Test speed $[\mathrm{mm} / \mathrm{min}]$

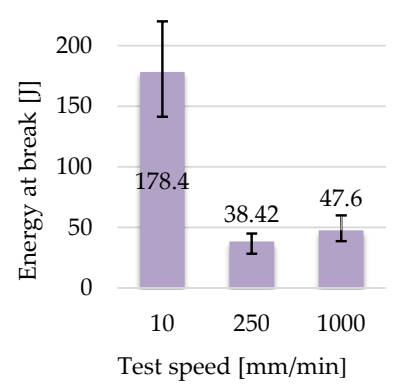

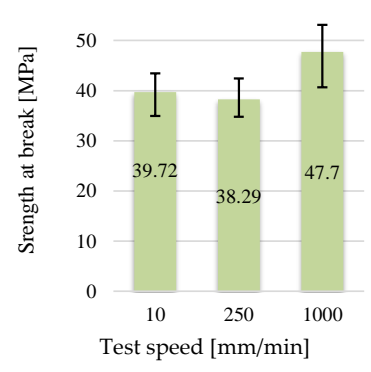
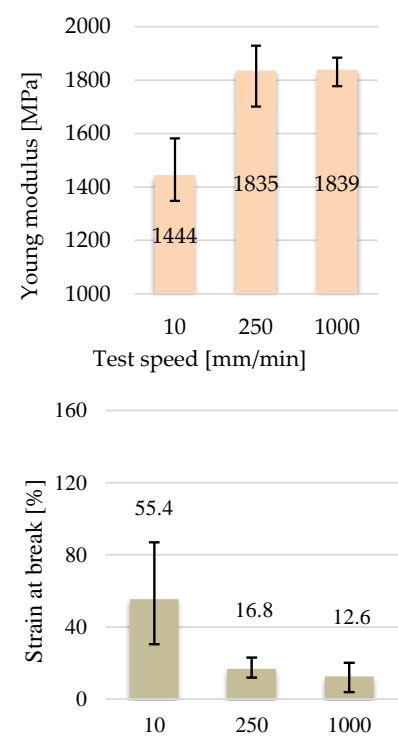

Test speed $[\mathrm{mm} / \mathrm{min}]$

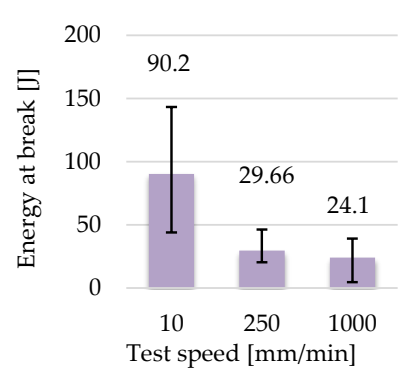

Figure 5. Mechanical characteristics for tested materials as a function of test speed

The variation of the values obtained for the breaking strength parameter is insignificant for material G (Fig. 5, third column), but still retains the upward trend with increasing test speed, so for the lowest test speed $(10 \mathrm{~mm} / \mathrm{min})$ the lowest was obtained average value for this parameter $(34.17 \mathrm{MPa})$ and highest $(35.7 \mathrm{MPa})$ for the highest test speed $(1000 \mathrm{~mm} / \mathrm{min})$. The capping of the average breaking stress value for a test speed range (around $34 \mathrm{MPa}$ ) is not characteristic of many materials [58], [59]. The same tendency is maintained by the modulus of elasticity, so for the lowest test speed, $\mathrm{E}=1594$ $\mathrm{MPa}$, for $\mathrm{v}=250 \mathrm{~mm} / \mathrm{min}(\mathrm{E}=1623 \mathrm{MPa})$ and for $\mathrm{v}=1000 \mathrm{~mm} / \mathrm{min}(\mathrm{E}=1625 \mathrm{MPa})$ the increase being only $1.94 \%$ compared to the lowest test speed, therefore the fact that this parameter is so little influenced by the test speed makes G look quite particular for a plastic material [60], even for a blend.

The other two parameters (strain at break and energy at break) show the same tendency of the values, namely the highest values (118.7\% and $178.4 \mathrm{~J}$, respectively) were obtained for the lowest test speed $(10 \mathrm{~mm} / \mathrm{min})$, the scattering ranges obtained are also large, after which the values of these parameters have decreased substantially, which makes material $\mathrm{G}$ behave atypically compared to other plastics, because normally the values of these parameters should be to decrease with increasing test speed [58], [61]. 
The decrease of the deformation at break, from the lowest speed $(10 \mathrm{~mm} / \mathrm{min})$ to the speed $\mathrm{v}=250 \mathrm{~mm} / \mathrm{min}$ is characteristic of polymers, but the behavior of this characteristic in the range $250 \ldots 1000 \mathrm{~mm} / \mathrm{min}$ is atypical, the possible cause being the behavior the EPDM constituent and the cohesion between it, PP and PA6 [26].

For material $G$, the values of the strength at and elastic modulus show an increasing trend with the test speed $(250 \ldots 1000 \mathrm{~mm} / \mathrm{min})$ and yet the values obtained are lower than those of plain polyamide. This means that the elaborated blends have intermediate values for this characteristic, which would confirm the rule of mixtures.

For PA6 (Fig. 5, fourth column), the values obtained for the strength at break fall within a narrow range but with a tendency to increase the values, so the highest tensile test speed $(1000 \mathrm{~mm} / \mathrm{min}$ ) makes the values for the breaking strength increases by $20.1 \%$ for PA6 as compared to the value of the same parameter at $\mathrm{v}=10 \mathrm{~mm} / \mathrm{min}$. Some specimens of PA6 were broken at $24 . . .30 \%$ of its strain, but others were broken after about $90 \%$, however the scattering interval of the latter is very long, possibly due to the gaps obtained during processing, such of material having a slightly unpredictable behavior. The Young modulus depends on the test speed, the obtained values increase with the increase of the latter, so, at the lowest test speed $(10 \mathrm{~mm} / \mathrm{min})$, the lowest value was obtained for this parameter (1444 MPa), and for the others two speeds, the values show insignificant differences, namely $1835 \mathrm{MPa}(250 \mathrm{~mm} / \mathrm{min})$ and $1839 \mathrm{MPa}(1000 \mathrm{~mm} / \mathrm{min})$.

Each characteristic is analyzed based on the following formula, written here only for strength at break:

$$
\frac{\sigma_{r(1000)}-\sigma_{r(10)}}{\sigma_{r(10)}} \cdot 100[\%]
$$

where $\sigma_{r_{(10)}}$ is the value for strength at break at test speed $\mathrm{v}=10 \mathrm{~mm} / \mathrm{min}$ and $\sigma_{r_{(1000)}}$ is the value for strength at break for the tesit speed $\mathrm{v}=1000 \mathrm{~mm} / \mathrm{min}$. The results of the comparative data are given in Table 4.

Table 4. Percentage difference in comparing results for two test speed, $10 \mathrm{~mm} / \mathrm{min}$ and $1000 \mathrm{~mm} / \mathrm{min}$

\begin{tabular}{cccc}
\hline Test & PP & G & H \\
\hline$\frac{E_{(1000)}-E_{(10)}}{E_{(10)}} \cdot 100[\%]$ & 10.32 & 1.97 & 3.82 \\
$\frac{\sigma_{r(1000)}-\sigma_{r(10)}}{\sigma_{r(10)}} \cdot 100[\%]$ & 59.25 & 4.51 & 27.74 \\
$\frac{\varepsilon_{r(1000)}-\varepsilon_{r(10)}}{\varepsilon_{r(10)}} \cdot 100[\%]$ & -31.88 & -75.37 & 44.23 \\
$\frac{E_{r(1000)}-E_{r(10)}}{E_{r(10)}} \cdot 100[\%]$ & -16.10 & -73.29 & 107.97 \\
\hline
\end{tabular}

The interface of the constituents influences the development of the continuous phase but also of the co-continuous morphologies. The morphology of the dispersed phase is the one that has a decisive role in establishing the mechanical properties of immiscible polymers. During shearing, the droplet size is a direct result of the fragmentation of the initial droplets and the coalescence process (merging/reuniting of several droplets). Among the morphologies resulting from blends with immiscible constituents, cocontinuous structures are more promising because they give a material in which the components intervene synergistically in establishing the set of properties [26].

The addition of small amounts of adhesives, elastomers can influence the morphology of immiscible blends, either by reducing the droplets of the dispersed phase, or by promoting the formation of co-continuous morphologies. These improve the breaking behavior, having an effect of increasing the strength at break and the energy at break. A stable co-continuous morphology balances or counterbalances the resistance that 
would have been created in the absence of particles between the immiscible phases of the blend [62], [26].

\section{Analysis of the blend morphologies}

The break surfaces of specimens were coated with gold in order to increase the local electrical conductivity, the result being a better resolution of the SEM images.

In blends with PP matrix, the deformation results from a combination of amorphous hyperelastic phase and crystalline plasticity [21]. The PA6 phase is also capable of deforming plastically, but its yield strength falls within the plastic domain and has a much higher value than that of PP [24]. Consequently, in PP/PA6 blends, the isolated particles of PA6 show a lower deformation than the PP matrix, which leads to surface tension concentrations. In contrast, insulated POE nodules deform slightly due to the compatibility properties of the rubber.

The immiscibility of PP + PA6 blends can lead to a reduction of strain at break, this being also reported by other authors [17], [25], [35]. This behavior can be explained by a process of delamination, detachment of the phases from the cooling phase and then on loading, due to the reduced interfacial adhesion between the constituents [26].

Specimens made of PA6 had large central elongated ellipsoidal cavities that were obtained during processing and not under load. Pure polyamide is difficult to process by injection into the mold taking into account the parameters chosen in this paper [60]. Macro-scale gaps may occur due to inadequate processing parameters. Cavities also occur if the volumes on the surface of the injected elements solidify too quickly and the contraction is located inwards. Therefore, the cavities are associated with molds that are too cold to melt and specific recommendations of the injected polymer. Causes of cavities can be: insufficient melting volume in the machine, incorrect processing conditions (pressure, temperature, time and speed of injection and maintenance), wet materials, so their appearance can be avoided by redesigning the injection process. Specialists [63], [64], recommend: drying the constituents, increasing the melting temperature and more precise control over the processing areas, increase of the mold temperature, increase of the injection and maintenance pressure, increase of the injection time, increase of the supply in the melt distribution system, especially if the buffer zone is small, decrease of the supply area if the buffer zone is too big, relocation of the intake paths of melting, removal of thick-walled sections [26].

Figure 6 shows typical details by comparing the aspect of broken surfaces of PP and PA6 specimens, at the lowest test speed, with a significant difference of the break aspects, especially when comparing images at high magnification

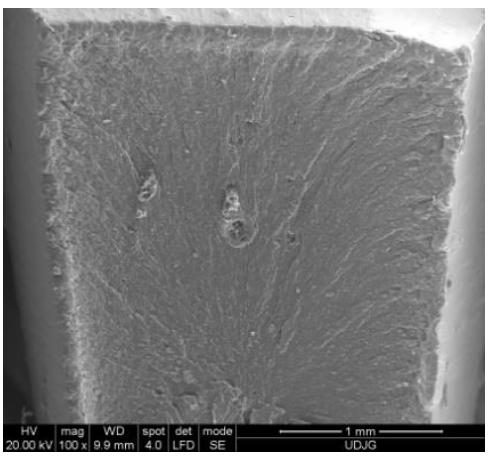

(a)

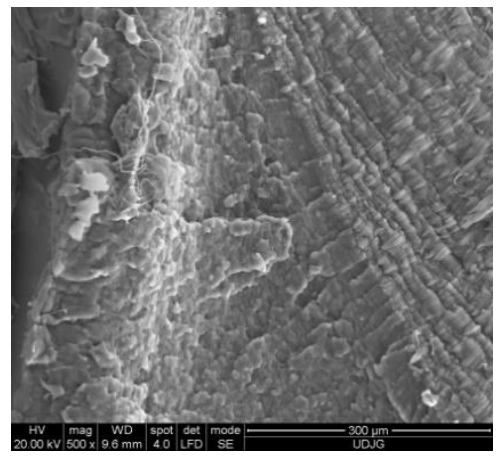

(b)

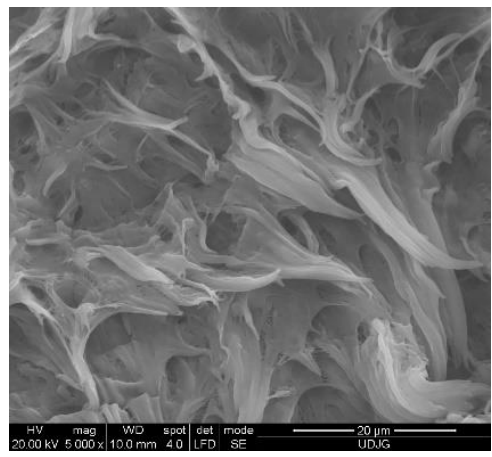

(c) 


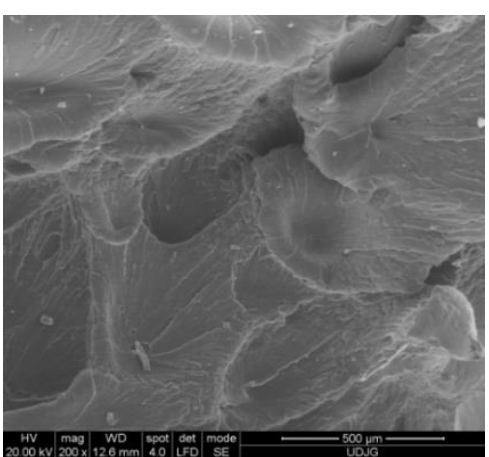

(d)

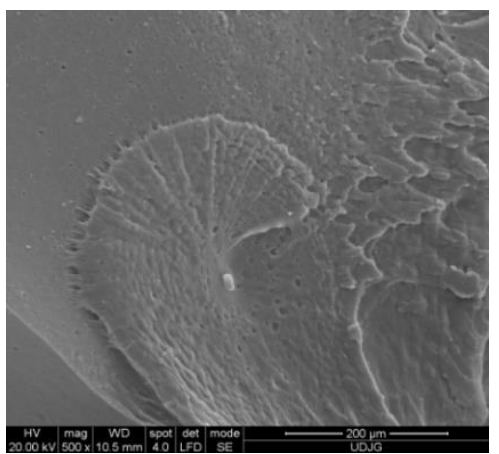

(e)

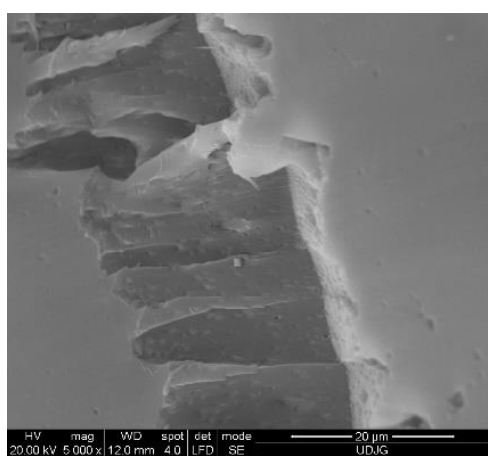

(f)

Figure 6. Details of the broken surface for v = $10 \mathrm{~mm} / \mathrm{min}$ : (a), (b) and (c) for PP; (d), (c) and (f) for PA6

PA6 has a very ductile nature for low test rate $(10 \mathrm{~mm} / \mathrm{min})$ (Fig. 6d, e and f), but becomes less ductile for higher rates $(250 \mathrm{~mm} / \mathrm{min}$ and $1000 \mathrm{~mm} / \mathrm{min}$.

Figure 7 shows typical details by comparison of the rupture of some polypropylene and polyamide specimens, at the test speed of $250 \mathrm{~mm} / \mathrm{min}$. The fibrillation process at the level of micro volumes is no longer accentuated at the test speed $\mathrm{v}=250 \mathrm{~mm} / \mathrm{min}$ because it can be seen that the material yields over the entire surface. In contrast, the PP material has a breaking surface specific to a thermoplastic polymer. At low test speed $(\mathrm{v}=10$ $\mathrm{mm} / \mathrm{min}$ ), the breaking surface of PP shows slightly pronounced local flows (the wavy surface on the right), which means that there are qualitatively different areas at the polymer level (average molecular and degree of mass crystallinity). At higher test speeds, cavities appeared due to the uniaxial stress, highlighting different flows of the polymer. At $\mathrm{v}=1000 \mathrm{~mm} / \mathrm{min}$, these stress cavities are smaller and rarer, and the breaking surface has a brittle appearance.

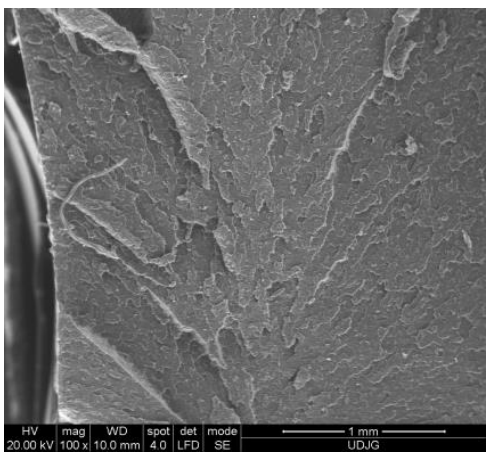

(a)

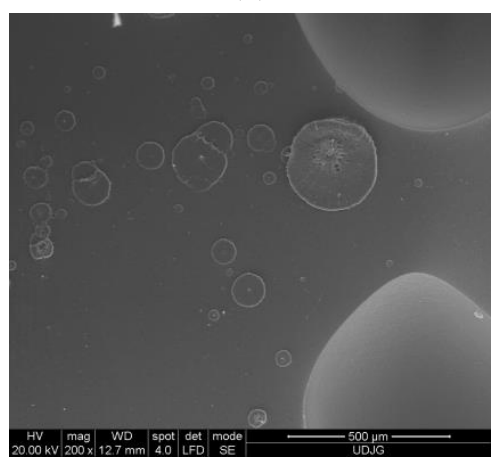

(d)

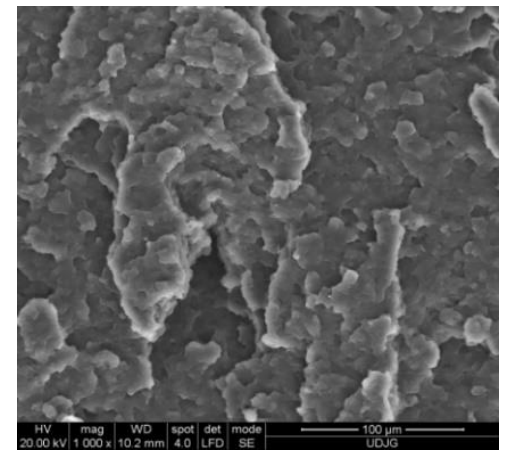

(b)

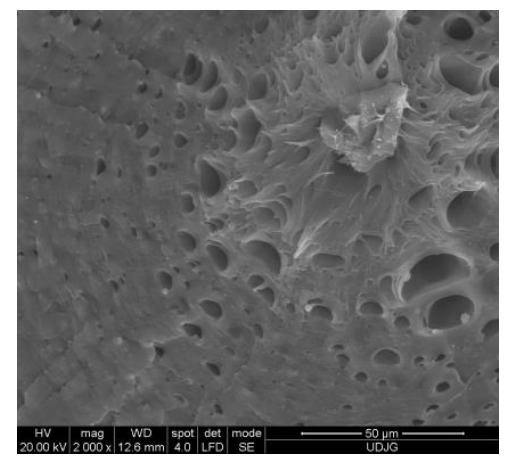

(e)

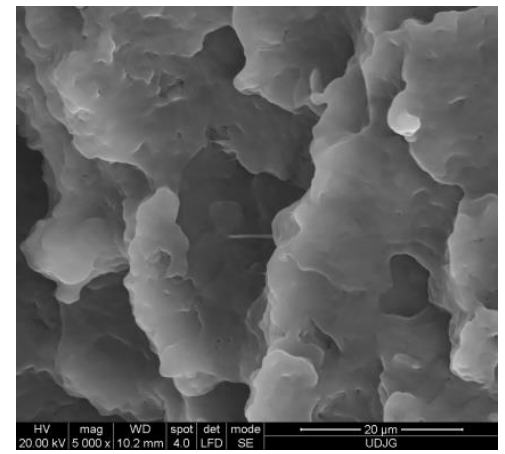

(c)

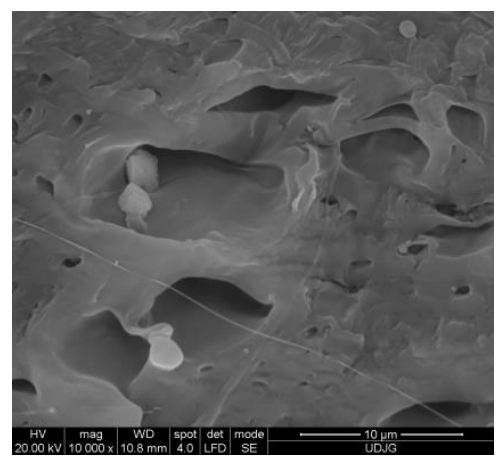

(f)

Figure 7. Details of broken surface for $\mathrm{v}=250 \mathrm{~mm} / \mathrm{min}$, at different magnification scales: (a) PP; (b) PA6

Typical details of broken surfaces are given for PP (Fig. 8a) and PA6 (Fis. 8b) specimens, at the test speed of $1000 \mathrm{~mm} / \mathrm{min}$. At this test rate, the presence of fibrils may be rare, and they are thin, suggesting a sudden stretching of a more plastic micro-volume. 
You can also see on the SEM images very small pores that appeared as a result of the bandtype landslides on the broken surface.

Figure $8 \mathrm{~b}$ shows the breaking of PA6 specimens at the test speed $1000 \mathrm{~mm} / \mathrm{min}$, but also the presence of processing cavities in some specimens, which negatively affects the performance of the material. From tested PA6 specimens, approximately $20 \%$ were with cavitation. Decohesion (detachment) of particles from the matrix is an important mechanism of deterioration in polymeric blends with ductile matrix (such as PA6) and weakly adherent particles (such as PP when constituting the dispersed phase). This mechanism also occurs in PP + PA + POE blends [22]. The improvement of the behavior of such blends can be done by increasing the adhesion of the intermediate phases between the matrix and the dispersed constituent, by adding compatibilizing agents in PA + PP (clays, fibers, polymer blocks or elastomers).

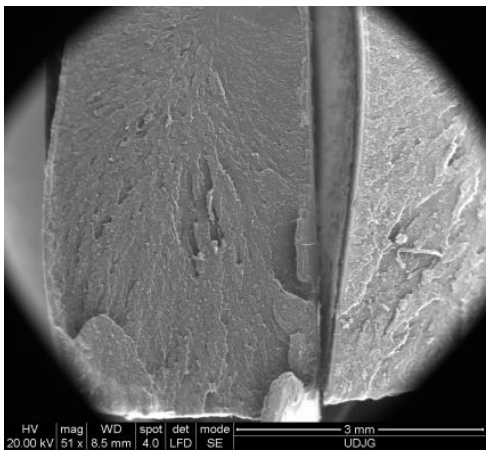

(a)

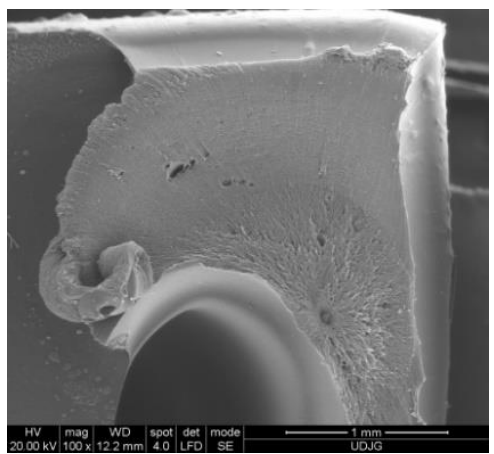

(d)

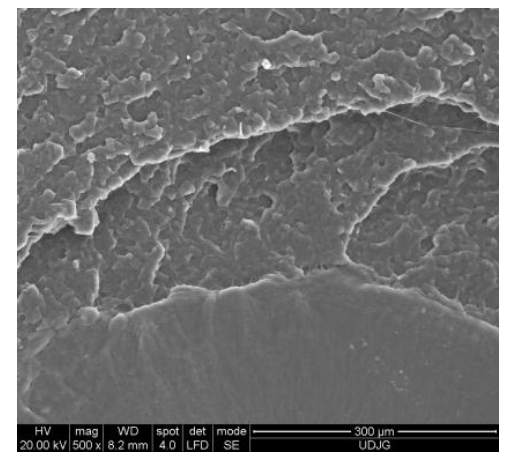

(b)

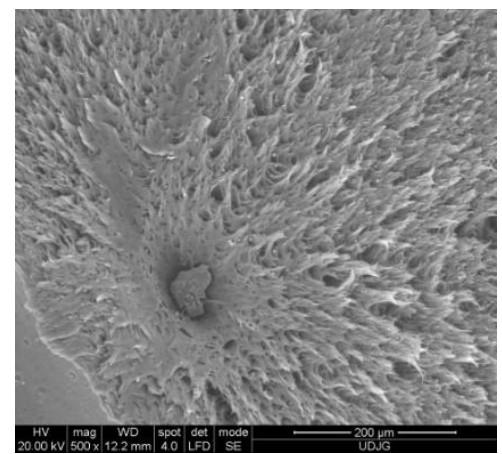

(e)

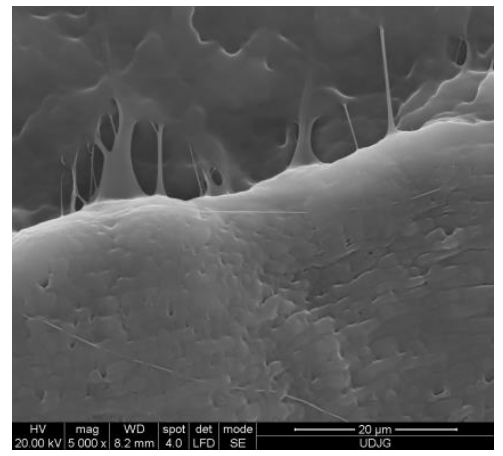

(c)

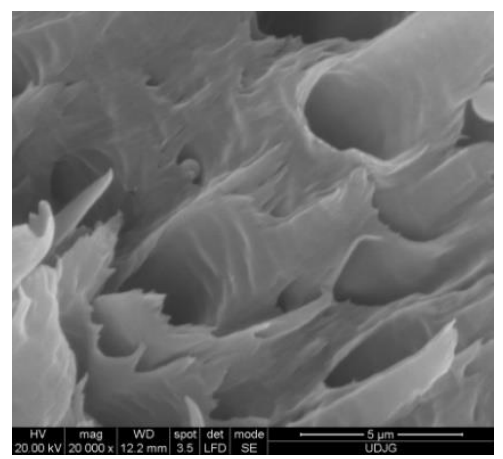

(f)

Figure 8. Details of broken surface for $\mathrm{v}=1000 \mathrm{~mm} / \mathrm{min}$, at different magnification scales: (a) PP; (b) PA6

The influence of the compatibilizer concentration on the morphology of blends with PP + PA6 + elastomeric compatibilizer was also evaluated by Li and Xie [65] on blends (PP + PP-g- (MAH-co St)) + PA6 + SEBS $(70+15+15)$, in which the component (PP + PP-g(MAH-co St)) had concentrations from $0 \%$ to $70 \%$.

The cavitation of isolated elastomer particles and elastomer intermediate layers are the main mechanisms of damage and volume expansion of polymer blends. As the cavitation in PA6 particles was found in the studies of Bai and G'Sell [21-24], but also in other authors [66-69] the deformation damage is controlled by the elastomer cavitation and the interfacial delamination (detachment) [22], [26].

The introduction of an elastomeric agent to increase the resilience in polymeric blends leads to an increase in impact resistance due to the decrease in stiffness and strength. On the contrary, if a compatibility is desired to increase the strength of a PA6 + elastomer blend, Kelnar et al. [70] found that the morphology of the dispersed phase must be small. TEM images showed the formation of hard shell-like particles (elastomer surrounded by clay micro-platelets), which improved the resilience of the elastomer. The result was a simultaneous increase in strength, resilience and dimensional stability. 
The cavitation of isolated elastomer particles and elastomer intermediate layers are the main mechanisms of damage and volume expansion in polymer blends. As the cavitation in PA6 particles was found in the studies of Bai and G'Sell [22], [23], [24], but also in [71], [72], the deformation damage is controlled by the elastomer cavitation and the interfacial delamination (detachment) [26]. For low-content blends, intermediate POE layers are very thin and PA6 particles are almost spherical. The crack develops easily and leaves a smooth surface. In contrast, for blends with high-alloy content, the intermediate layer of POE is thick and PA6 particles are much elongated, resulting in a rough surface. Therefore, to improve the impact strength of polyamides, an impact strength modifier, EPDM was included in the blend (8\% EPDM in material $\mathrm{H}$ and 28\% EPDM in material G).

Figures 9 and 10 present SEM images with the magnification aspects of $x 100$ and x2000, respectively, for the blends $\mathrm{H}(12 \%$ PA6) and G (40\% PA6), from where the fragile break for material $\mathrm{H}$ is pointed out. For material $\mathrm{G}$, the appearance micro-volumes of material strongly deformed can be observed; the break is initiated in small spots, with elongated and thinner shape towards the break point. This aspect may be considered a positive one because the material hardens locally and deforms more until break, also incorporating higher energy till break.

Material H (Fig. 9) shows brittle ruptures for all test speeds: (a) v=10 mm/min, (b) $\mathrm{v}=250 \mathrm{~mm} / \mathrm{min}$ and (c) $\mathrm{v}=1000 \mathrm{~mm} / \mathrm{min}$. PA6 droplets could be observed in the broken surfaces, with dimensions of the order of microns, the largest having 10-20 microns, particles partially attached to the PP matrix with EPDM. The presence of EPDM, even at a low percentage of $8 \% \mathrm{wt}$, improved the adhesion between the PP + EPDM matrix and the PA6 droplets. In the case of droplets that do not adhere well to the matrix, due to the stress, fixing fibrils, slightly elongated, can be observed. Figure $9 \mathrm{~b}$ shows typical drops of PA6, partially trapped in the PP matrix (having a more fragile nature).
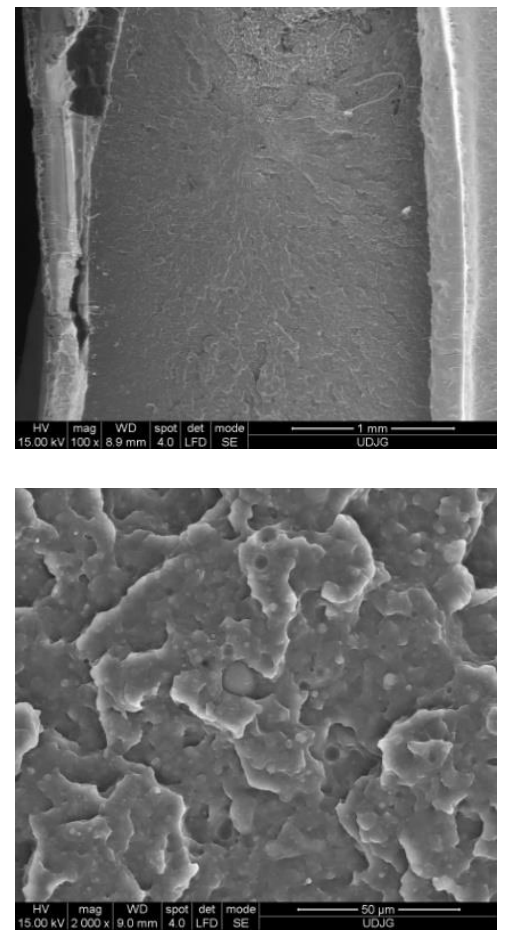

(a) $10 \mathrm{~mm} / \mathrm{min}$
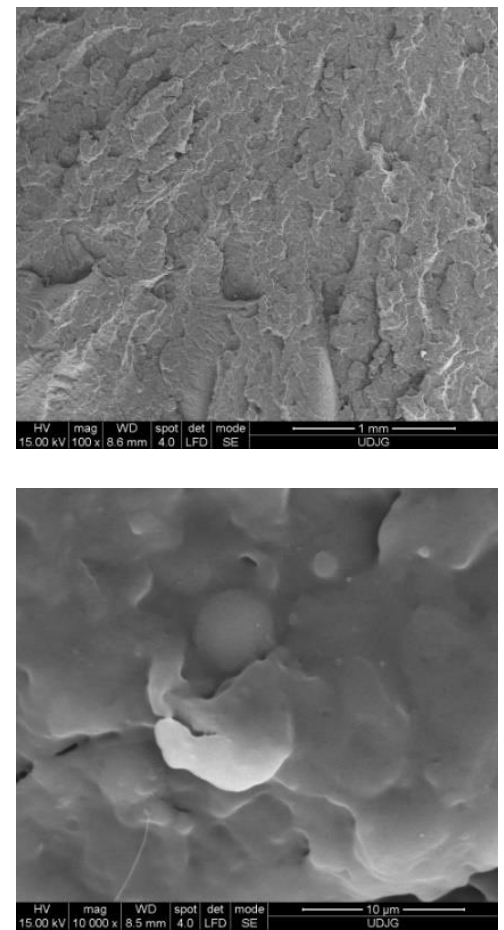

(b) $250 \mathrm{~mm} / \mathrm{min}$
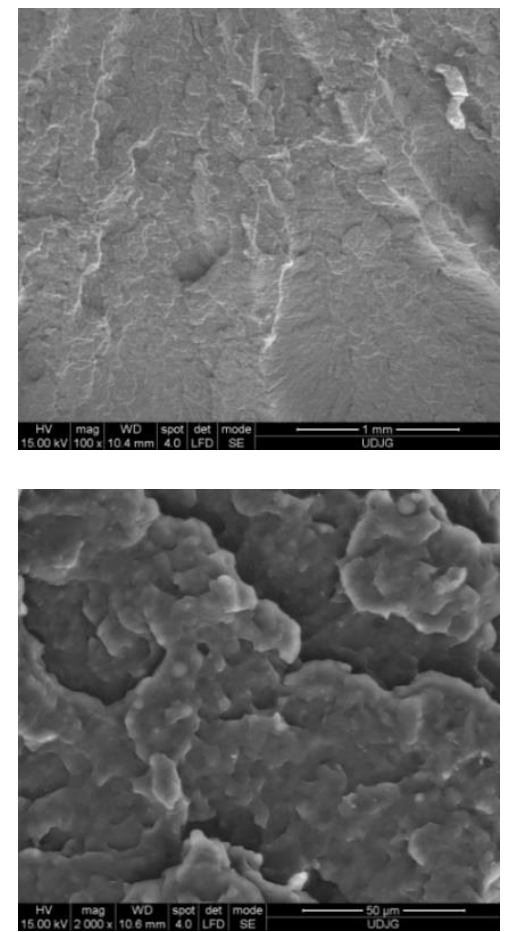

(c) $1000 \mathrm{~mm} / \mathrm{min}$

Figure 9. Details of broken surfaces for specimens made of material $\mathrm{H}$ tested at different test speed: (a) 10 $\mathrm{mm} / \mathrm{min}$; (b) $250 \mathrm{~mm} / \mathrm{min}$ and (c) $1000 \mathrm{~mm} / \mathrm{min}$, with two different magnifications. 

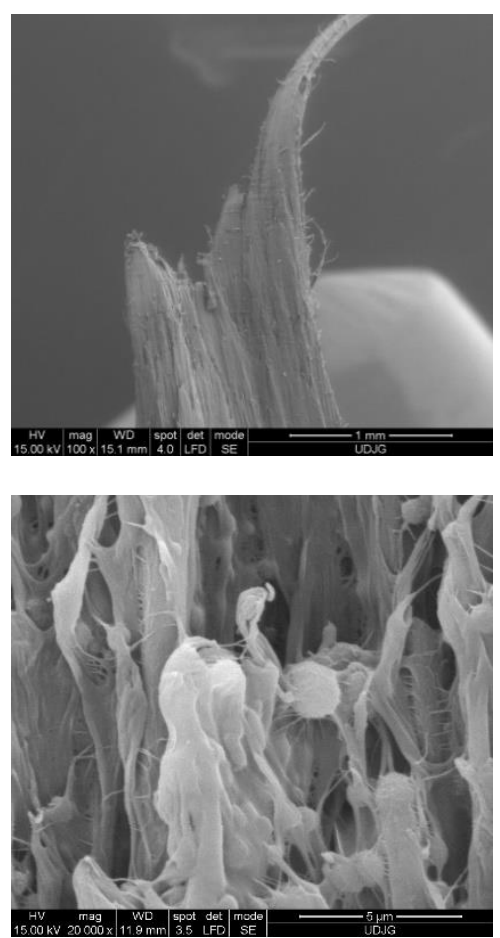

(a) $10 \mathrm{~mm} / \mathrm{min}$
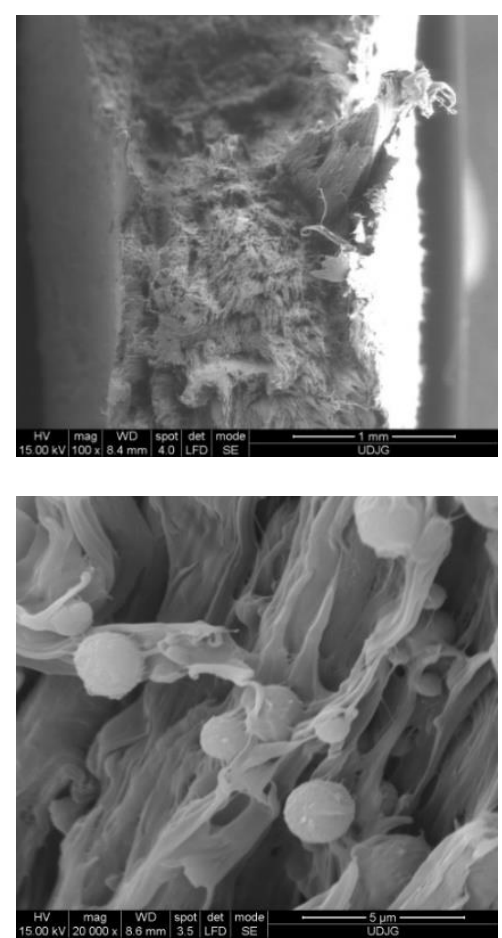

b) $250 \mathrm{~mm} / \mathrm{min}$
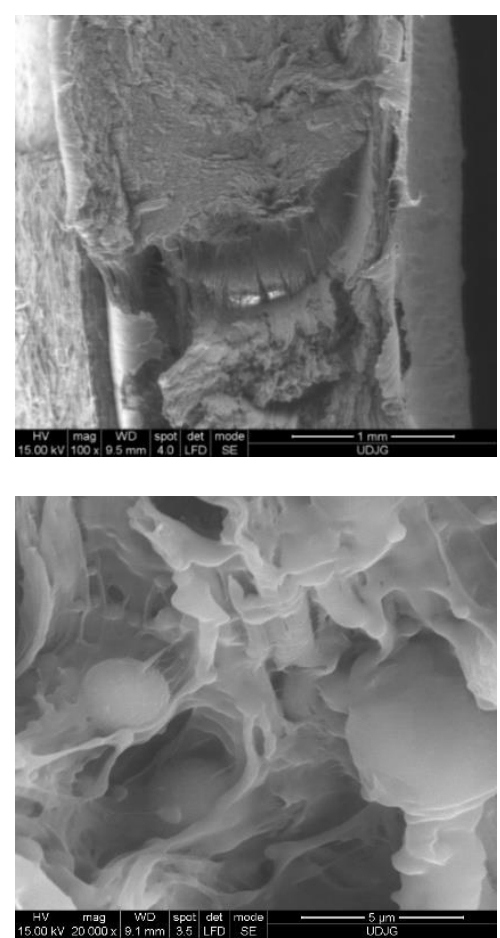

(c) $1000 \mathrm{~mm} / \mathrm{min}$

Figure 10. Details of broken surfaces for specimens made of material G tested at different test speed: (a) 10 $\mathrm{mm} / \mathrm{min}$; (b) $250 \mathrm{~mm} / \mathrm{min}$ and (c) $1000 \mathrm{~mm} / \mathrm{min}$, with two different magnifications.

For the blend G (Fig. 10), a phase change occurs, so the dispersed phase is PP and its droplet size seems to be quite uniform. The break of the specimen after the tensile test takes place after elongation in the matrix. Second line of SEM images in Fig. 10 shows much larger details (x20000) of tensile fracture surfaces for material G, showing a particular structure, the micromorphology of the fracture surface being with many and longer fibrils at low test speed (Fig. 10a), but being slightly influenced by the higher test speeds (Fig. 10b and c), with shorter fibrils and less visible deformation of the matrix. On the breaking surface of material G, the multitude of droplets (with dimensions of about 10 microns) can be observed and these droplets seem to be trapped in the PA6 matrix through fibrils generated from the matrix.

After performing an EDX analysis (Fig. 11), the constituents of the blends could be identified, so the droplets or islands could be identified as having PA6 if there is a concentration of nitrogen $(\mathrm{N})$ (specific for polyamide) or not (specific for PP and EPDM). In Figure 12, the droplets in the blend $\mathrm{H}$ have in their composition the element nitrogen $(12.11 \% \mathrm{wt})$, this being characteristic for polyamide $\left(\mathrm{C}_{6} \mathrm{H}_{11} \mathrm{NO}\right)_{\mathrm{n}}$.

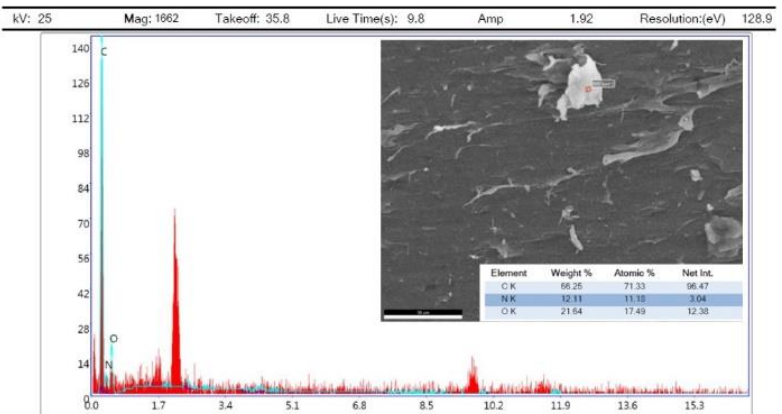

(a)

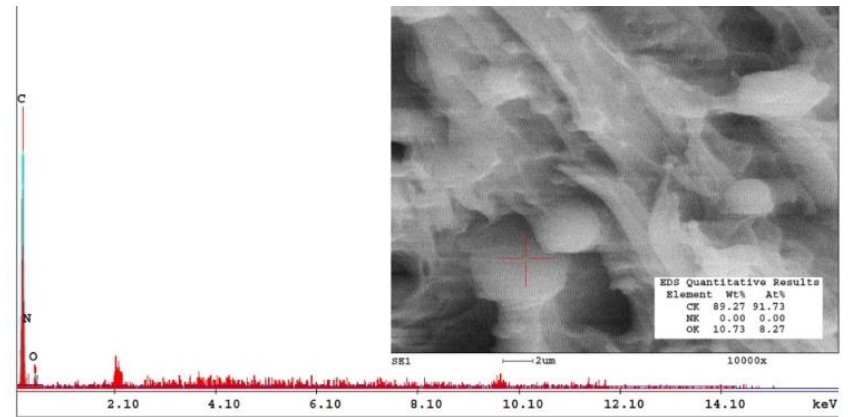

(b)

Figure 11. EDX analysis for morphology configuration: (a) confirmation of droplets made of PA6 in a matrix de PP (material H) and (b) confirmation of the droplets made of PP in a matrix of PA6 (material G) [26] 
For material G, the yield is due to the higher percentage (42\% wt) of PA6, and the study of SEM images with EDX analysis found the reversal of the role of constituents: PA6 becomes matrix and PP is dispersed as droplets. It is observed that the PA6 matrix has large local deformations in the tensile breaking section. It is observed that the droplets do not have nitrogen in their composition and knowing that the PP and PA6 polymers are immiscible, it results that the droplets are made of PP and the (visibly ductile) matrix of PA6.

At higher test speeds, the appearance is much different between PP and $\mathrm{H}$, on one hand, and G and PA6, on the other hand. The first two materials have brittle fractures, with fractured, rough surfaces and the other two have visible necking and local material yielding. The aspect of material failure was also kept for Charpy tests [50], brittle for materials PP and H and ductile for materials G and PA6.

\section{Conclusions on tensile characteristics}

Figure 12 shows four mechanical characteristics, in the sense of increasing PA6 content ( 0 for PP, $12 \%$ for $\mathrm{H}, 42 \%$ for $\mathrm{G}$ and $100 \%$ for PA6).
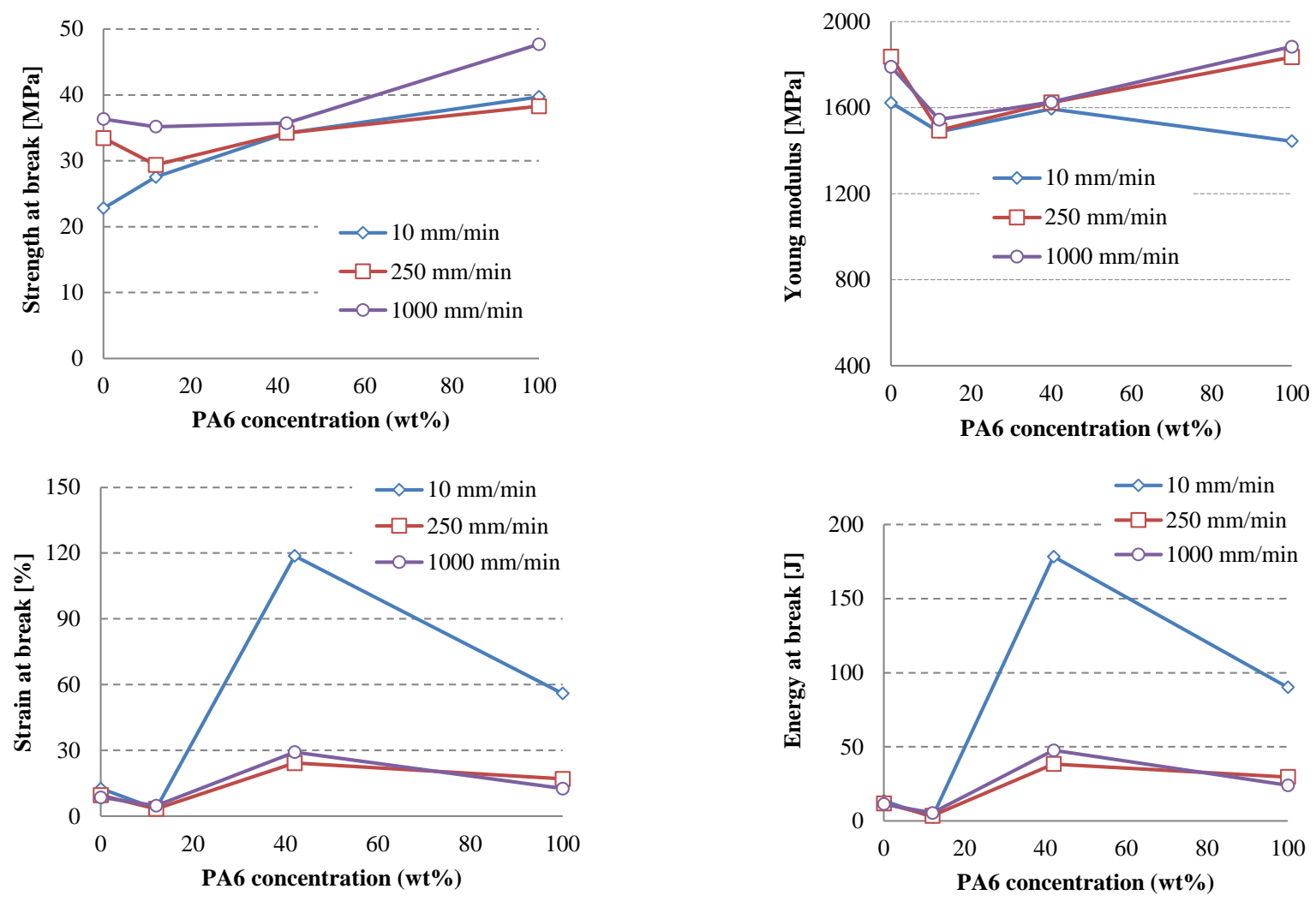

Figure 12. Mechanical characteristics for tested materials (average values)

Among the studied parameters, the slightly sensitive to the test speed are the modulus of elasticity and tensile strength at break. As concerning the other two parameters (energy at break and strain at break), their values are well differenciated for $\mathrm{v}=10 \mathrm{~mm} / \mathrm{min}$ and for the other two test speeds $(\mathrm{v}=250 \mathrm{~mm} / \mathrm{min}$ and $\mathrm{v}=1000 \mathrm{~mm} / \mathrm{min})$, their values being close.

Analyzing Fig. 12, the atypical behavior of material $\mathrm{H}$ as compared the other studied blend $(G)$ can be observed, namely, the obtaining of the lowest values of energy at break, which makes this blend not recommended in applications where the energy at break is a decisive factor. If the values of the energy at break obtained for $\mathrm{v}=10 \mathrm{~mm} / \mathrm{min}$ are ignored because, in practice, failure mechanisms at these rates are not often encountered and not accepted in machine components, the other values are grouped in the following ascending 
order for all rates $(250 \ldots 1000 \mathrm{~mm} / \mathrm{min}): \mathrm{H}, \mathrm{PP}, \mathrm{PA6}, \mathrm{G}$. Material G, as developed in [26], [60], [50] have promising results as moderate impact-resistant material. The tensile strength at break shows a tendency to increase the average values with the increase of polyamide concentration, but yet simple polyamide has the highest average values of the tensile strength at break.

At low test rate $(\mathrm{v}=10 \mathrm{~mm} / \mathrm{min})$, the materials with high energies at break are ductile materials (G and PA6), with values very different from those of simple polypropylene and $\mathrm{PP}$ matrix blend (material $\mathrm{H}$ ). Except for the average value obtained for material $\mathrm{G}$ for the strength at break (which, for every test rate has a value close to that of PA6), it can be seen that the other three studied characteristics have even higher average values than the basic constituent (PA6).

Figure 12 points out the increase of the average value of energy at break with the increase of the test speed for material $\mathrm{H}$, but for the other three materials, the increase of the test speed causes the energy at break to decrease much from the lowest test (10 $\mathrm{mm} / \mathrm{min}$ ), the highest value being obtained for material $\mathrm{G}(38.4 \mathrm{~J})$.

The strain at break has the same trend as that for energy at break for all tested materials, namely the appearance of high average values at the lowest test speed, which is also normal because the slower a load is applied to the test specimens, the specimen has time to deform and, thus, large strains occurs under low stresses.

The values of tensile strength at break (at $\mathrm{v}=250 \mathrm{~mm} / \mathrm{min}$ ) are quite close for all materials, the highest value being obtained for PA6 (38.3 MPa).

The modulus of elasticity is slightly sensitive to the test speed (except for $\mathrm{v}=10$ $\mathrm{mm} / \mathrm{min}$ ), but the PA6 concentration influences this characteristic quite a lot. At $\mathrm{v}=250$ $\mathrm{mm} / \mathrm{min}$, the highest values of this parameter were obtained for the base polymers.

Lower values for energy at break in traction are also be caused by the formation of cavitations during processing and/or cooling (especially in the case of PA6). Mold injection may be the main cause of cavities in many polymers [69].

As concerning the modulus of elasticity (Fig. 12), it can be seen that the base polymers still have the highest average values and that this characteristic is very little sensitive to the test speed and the scattering range of the values obtained for PP is very small. The values of the blends for this parameter are in line with those obtained for the base polymers.

Of the two blends, material $\mathrm{G}$ has values well above the blend $\mathrm{H}$, but the spread range of the obtained values (especially for the energy at break and strain at break) is quite large.

If the average values obtained for energy at break for $\mathrm{v}=10 \mathrm{~mm} / \mathrm{min}$ are not taken into account, it can be seen that, as the test rate increases from $250 \mathrm{~mm} / \mathrm{min}$ to 1000 $\mathrm{mm} / \mathrm{min}$, the values increase very slightly for the blends, by $23.96 \%$ for blend $\mathrm{G}$.

The large gradient occurs when increasing the test rate from $\mathrm{v}=10 \mathrm{~mm} / \mathrm{min}$ to $\mathrm{v}=$ $250 \mathrm{~mm} / \mathrm{min}$, respectively $\mathrm{v}=1000 \mathrm{~mm} / \mathrm{min}$, so the values of energy at break for the material $\mathrm{G}$ decrease from $178.4 \mathrm{~J}$ to $38.4 \mathrm{~J}$, respectively $47.6 \mathrm{~J}$.

The decrease in values between the test rates of $10 \mathrm{~mm} / \mathrm{min}$ and $250 \mathrm{~mm} / \mathrm{min}$ is specific to plastics. The increase of the energy at break for material $\mathrm{G}$ with the increase of the test rate is also atypical. At $\mathrm{v}=1000 \mathrm{~mm} / \mathrm{min}$, the value of energy at break increased by $23.96 \%$ as compared to that obtained at $\mathrm{v}=250 \mathrm{~mm} / \mathrm{min}$.

Following this documentation from the literature, it can be concluded that the immiscibility of polymer blends (in this case, PP + PA6) can be avoided by using compatibilizing agents, namely the addition of an elastomer that would help to produce a morphology suitable for increasing mechanical properties, especially those related to the resistance at moderate impact.

Author Contributions: For research articles with several authors, a short paragraph specifying their individual contributions must be provided. The following statements should be used "Conceptualization, L.D., G.G.O. and A.M.M; methodology, M.B., G.C.C.and L.C.T.; software L.C.T.; validation, L.D, G.C.C. and M.B.; formal analysis, L.C.T.; investigation, X.X.; resources, X.X.; data curation, X.X.; writing - original draft preparation, L.C.T.; writing - review and editing L.C.T., G.G.O. and A.M.M; 
visualization, L.C.T. and A.M.M; supervision, L.D.; project administration, M.B. and G.C.C.. All authors have read and agreed to the published version of the manuscript.".

Funding: Please add: "This research received no external funding"

Acknowledgments: The results of this work will be also presented to the 9th edition of the Scientific Conference organized by the Doctoral Schools of "Dunărea de Jos" University of Galati (SCDSUDJG) http://www.cssd-udjg.ugal.ro/ that will be held on 10th and 11th of June 2021, in Galati, Romania.

This work is supported by the project ANTREPRENORDOC, in the framework of Human Resources Development Operational Programme 2014-2020, financed from the European Social Fund under the contract number 36355/23.05.2019 HRD OP /380/6/13 - SMIS Code: 123847.

Conflicts of Interest: “The authors declare no conflict of interest."

\section{References}

1. Xavier, S. F.; Chapter 10. Properties and Performance of Polymer Blends. In Polymer Blends Handbook, Utracki L.A., Wilkie C.A. (eds.), Springer Science+Business Media Dordrecht, 2014, pp 861-950 doi:10.1007/978-94-007-6064-6_12.

2. Utracki, L. A. Polymer Blends Handbook, Kluwer Academic Publishers, Dordrecht, London, ISBN 1-4020-1114-8 Set, 2002.

3. McKeen, L.W. The effect of temperature and other factors on plastics and elastomers, William Andrew Inc., 2008.

4. Arridge, R.G.C., Theoretical aspects of polymer blends and alloys, Folkes M. J., Hope P. S. (Eds), Polymer blends and alloys. Blackie Academic and Professional, London, 1993, pp 126-162

5. Ou, B., Li, D., Liu, Y. Compatibilizing effect of maleated polypropylene on the mechanical properties of injection molded polypropylene/polyamide 6/functionalized-TiO2 nanocomposites, Composites Science and Technology 2009, 69, 421-426.

6. Paul, D. R., Newman, S., Polymer Blends, Academic Press, New York, 1978

7. Sharma, K. R. Polymer Thermodynamics Blends, Copolymers and Reversible Polymerization, CRC Press Taylor \& Francis Group, 2012, pp 3-17, ISBN 13: 978-1-4398-2640-9.

8. Han C. D. 2007 Rheology and Processing of Polymeric Materials. Volume 1: Polymer Rheology, 707 pages, and Volume 2: Polymer Processing. 579 pages, research monograph. Oxford University Press, 2007.

9. Bradley, R., Radiation Technology Handbook, Marcel Dekker, New York, 1984.

10. Utracki, L. A., History of commercial polymer alloys and blends (From a perspective of the patent literature). Polym. Eng., 1995, $35,1-17$.

11. Lin, T. A., Limin, B., Lin, M.-C., Lin, J.-Y., Lou, C.-W., Line, J.-H., Impact-resistant polypropylene/thermoplastic polyurethane blends: compatible effects of maleic anhydride on thermal degradation properties and crystallization behaviors, 2019.

12. Grob M. C., Plastic additives: an answer for the new trends in the plastic industry, BASF Schweiz AG, Tagung Kunststofftechnologie (HTA-FR), Fribourg, Switzerland, 2012.

13. Polyamide (PA) or Nylon: Complete Guide (PA6, PA66, PA11, PA12...), https://omnexus.specialchem.com/selection-guide/polyamide

14. Biron M., Polypropylene: A chameleon that competes with engineering plastics \& many other materials, SpecialChem, https://omnexus.specialchem.com/tech-library/article/polypropylene-a-chameleon-that-competes-with-engineering-plasticsmany-other-materials, 2010

15. Rosato D., Polypropylene Performance Developments Move Forward!, https://omnexus.specialchem.com/tech-library/article/polypropylene-performance-developments-move-forward, 2019

16. Friedrich, K., Schlarb, A. K., Briscoe, B. J., Sinha, S. K. Tribology of Polymeric Nanocomposites. Tribology of Polymeric Nanocomposites 2013

17. Fu, S.Y, Feng, X.-Q., Lauke, B., Maid, Y.-W., Effects of particle size, particle/matrix interface adhesion and particle loading on mechanical properties of particulate-polymer composites, Compos. B. Eng., 2008, Volume 39, Issue 6, , $933-961$

18. Chow, W. S., Mohd Ishak Z. A., Polyamide blend-based nanocomposites: A review. EXPRESS Polym. Lett., 2015, 9(3), 211-232. doi: 10.3144/expresspolymlett.2015.22

19. Chow, W. S., Mohd Ishak Z. A., Karger-Kocsis J., Compatibilizing effect of maleated polypropylene on the mechanical properties and morphology of injection molded polyamide 6/ polypropylene/organoclay nanocomposites. Polymer, 2003, 44, 74277440 .

20. Botan, M., Danila, D., Pirvu, C., Deleanu, L., Influence of interface quality on stress and strain distribution in a micro cell of a composite, Mater. Plast., 2015, vol. 52, no. 1, pp 20-23, http://www.revmaterialeplastice.ro/pdf/BOTAN\%20M.pdf\%201\%2015.pdf

21. G'Sell, C., Hiver, J. M., Dahoun, A., Experimental characterization of deformation damage in solid polymers under tension, and its interrelation with necking, Int J Solids Struct INT J SOLIDS STRUCT, 2002, 39, pp. 3857-3872

22. Bai, S. L., Wang, G. T., Hiver, J. M., G'Sell, C., Microstructures and mechanical properties of polypropylene/polyamide 20266/polyethelene-octene elastomer blends. Polymer ,2004, 45, pp. 3063-3071.

23. Bai,S., G'Sell, C., Hiverc, J.-M., Mathieu,C., Polypropylene/polyamide 6/polyethylene-octene elastomer blends. Part 3. Mechanisms of volume dilatation during plastic deformation under uniaxial tension. Polymer, 2005, 46, 6437-6446. 
24. G'Sell, C., Bai, S.L., Hiver, J.M., Polypropylene/polyamide 6/polyethylene-octene elastomer blends. Part 2: volume dilation during plastic deformation under uniaxial tension. Polymer, 2004, 45, 5785-5792.

25. Palacios, J. K., Sangroniz, A., Eguiazabal, J. I., Etxeberria, A., Müller, A. J., Tailoring the properties of PP/PA6 nanostructured blends by the addition of nanosilica and compatibilizer agents, Eur. Polym. J., 2016, 85, 532-552.

26. Musteata, A. E., Characterization of two families of polymeric blends based on PA6 and PP by tensile and Charpy tests, PhD thesis, "Dunarea de Jos" University of Galati, Romania, 2020

27. Farahani, R. D., Ahmad Ramazani, S. A., Melt preparation and investigation of properties of toughened poly - amide\&66 with SEBS-g-MA and their nanocomposites, Mater. Des., 2008, 29, 105-111. doi:10.1016/j.matdes.2006.11.018

28. Kusmono, Mohd Ishak, Z. A., Chow, W. S., Takeichi, T., Rochmadi (2008) Influence of SEBS-g-MA on morphology, mechanical, and thermal properties of PA6/PP/organoclay nanocomposites. Eur. Polym. J., 2008, 44, 1023-1039, doi: 10.1016/j.eurpolymj.2008.01.019.

29. Mengual, A., Juarez, D., Balart, R., Ferrandez, S., PE-g-MA, PP-g-MA și SEBS-g-MA compatibilizers used in material blends, Procedia Manuf., 2017, 13, pp. 321- 326

30. Abitha, V.K., Rane, A.V., A review on EPDM/poly-olefinic blends and composites. Research E Reviews in Polymers, 2014, 5(3), 102-114

31. Antunes, C. F., Machado, A.V., Duin, M., Morphology Development and Phase Inversion during Dynamic Vulcanisation of EPDM/PP Blends. Eur. Polym. J., 2011, 47, 1447-1459.

32. Hasanpour, M., Mazidi, M. M., Aghjeh, M. K. R., The effect of rubber functionality on the phase morphology, mechanical performance and toughening mechanisms of highly toughened PP/PA6/EPDM ternary blends, Polym. Test., 2019, 79, https://doi.org/10.1016/j.polymertesting.2019.106018

33. Li, J., Blends of EPDM/thermoplastics, Lulea University of Technology, master thesis, 2008.

34. Ma, L., Yang, W., Guo, H., Effect of cross-linking degree of EPDM phase on the morphology evolu-tion and crystallization behavior of thermoplastic vulcanizates based on polyamide 6 (PA6)/ ethylene-propylene-diene rubber (EPDM) blends. Polymers, 2019, 11, 1375. doi:10.3390/polym11091375

35. Gonzales-Montiel, A., Keskkula, H., Paul, D. R., Impact-modified nylon 6/polypropylene blends: 3. Deformation mechanisms. Polymer, 1995, 36, 4621-4637.

36. Georgescu, C. (2012) Studii şi cercetări privind evoluţia parametrilor stratului superficial în procesele de frecare şi uzură ale unor materiale compozite cu matrice de polibutilentereftalat, teză de doctorat, Universitatea "Dunărea de Jos" din Galați

37. Herrero, M., Núñezb, K., Gallegob, R., Merinoa, J. C., Pastora, J. M., Sepiolite as replacement of short glass fibre in polyamide composites for injection moulding applications, Appl. Clay Sci., 2018, 162, 129-137.

38. García-López, D., Fernández, J. F., Merino, J. C., Santarén, J., María Pastor ,J., Effect of organic modification of sepiolite for PA6 polymer/organoclay nanocomposites. Compos Sci Technol, Elsevier, 2010, 70 (10), pp.1429. ff10.1016/j.compscitech.2010.05.020ff.ffhal-00657648f.

39. Xiang, F., Shi, Y., Li, X., Huang, T., Chen, C., Peng, Y., Wang, Y., Co-continuous morphology of immiscible high-density polyethylene/polyamide\&6 blend induced by multiwalled carbon nanotubes network. Eur. Polym. J., 2012, 48, 350-361. doi: 10.1016/j.eurpolymj.2011.11.013

40. Boțan, M. (2014) Caracterizarea mecanică și tribologică a unei clase de compozite polimerice, teza de doctorat, Universitatea "Dunărea de Jos" din Galați

41. Wahit, M. U., Hassan, A., Mohd Ishak, Z.A., Abu Bakar, A., The effect of polyethylene-octene elastomer on the morphological and mechanical properties of polyamide 6/polypropylene nanocomposites. Polym. Polym. Compos., 2005, 13, 795-805, doi: 10.1177/096739110501300805

42. Vranjes Penava, N., Rek, V., Fiamengo Houra, I., Effect of EPDM as acompatibilizer on mechanical properties and morphology ofPP/LDPE blends. J. Elastomers Plast., 2012, 45, 391-403, doi: 10.1177/0095244312457162

43. Wang, K., Wang, C., Li, J., Su, J., Zhang, Q., Du, R., Fu, Q., Effects of clay on phase morphology and mechanical properties in polyamide\&6/EPDM-g-MA/organoclay ternary nanocomposites. Polymer, 2007, 48, 2144-2154, doi: 10.1016/j.polymer.2007.01.070

44. Gallego, R., García-López, D., Merino, J. C., María Pastor, J., How Do the Shape of Clay and Type of Modifier Affect Properties of Polymer Blends?, J. Appl. Polym. Sci., 2013, 127(4),

45. Zhang, L., Wan, C., Zhang, Y., Investigation on morphology and mechanical properties of polyamide 6/ maleated ethylenepropylene-diene rubber/organoclay composites. Polym. Eng. Sci., 2009, 49, 209-216, doi: 10.1002/pen.21201

46. García-López, D., López-Quintana, S., Gobernado-Mitre, I., Merino, J.C., Pastor, J.M., Study of melt compounding conditions and characterization of polyamide 6/metallocene ethylene-polypropylene-diene copolymer/maleated ethylene-polypropylenediene copolymer blends reinforced with layered silicates, Polym. Eng. Sci., 2007, 47, Issue 7, https://doi.org/10.1002/pen.20782

47. Collar, E. P., Taranco, J., Areso, S., García-Martínez, J. M., Understanding the morphological changes in the polypropylene/polyamide 6 fifty/fifty blends by interfacial modifiers based on grafted atactic polypropylenes: microscopic, mechanical, and thermal characterization. Article ID 620362 Hindawi Publishing Corporation. J. Polym.,, 2015, pp. 1-25, http://dx.doi.org/10.1155/2015/620362

48. La Mantia, F. P., Ceraulo, M., Mistretta, M. C., Botta, L., Morreale, M., Compatibilization of polypropylene/polyamide 6 blend fibers using photo-oxidized polypropylene. Materials, 2019, 12, 81. doi:10.3390/ma12010081

49. Alexandrescu, L., Sönmeza, M., Georgescu, M., Niţuică, A., Ficai, R., Trusca, R., Gurău, D., Tudoroi, L., Polyamide/Polypropylene/graphene oxide nanocomposites with functional compatibilizers. Morpho-structural and physico-mechanical characterization. Procedia Structural Integrity, 2017, 5, 675-682. 
50. Pîrvu, C., Musteată, A. E., Ojoc, G. G., Deleanu, L., Numerical and Experimental Results on Charpy Tests for Blends Polypropylene + Polyamide + Ethylene Propylene Diene Monomer (PP + PA + EPDM), Materials, 2020, 13, 5837; doi:10.3390/ma13245837

51. Laoutid, F., Estrada, E., Michell, R. M., Bonnaud, L., Müller, A. J., Dubois, P., The influence of nanosilica on the nucleation, crystallization and tensile properties of PP/PC and PP/PA blends, Polymer, 2013, 54, 3982-3993.

52. Panaitescu, D. M., Frone, A. N., Nicolae, C., Micro- and nano-mechanical characterization of polyamide 11 and its composites containing cellulose nanofibers, Eur. Polym. J., 2013, 49, 3857-3866

53. Shen, C., Zhou, Y., Dou, R., Wang, W., Yin, B., Yang, M., Effect of the core-forming polymer on phase morphology and mechanical properties of PA6/EPDM-g-MA/HDPE ternary blends, Polymer, 2015, 56, 395-405

54. Shi, S., Huang, P., Nie, M., Wang, Q., Polypropylene/polyamide blend featuring mechanical interlocking via controlled interfacial diffusion and recrystallization. Polymer, 2017, 132, 23-30

55. Sui, G., Jing, M., Zhao, J., Wang, K., Zhang, Q., Fu, Q., A comparison study of high shear force and compatibilizer on the phase morphologies and properties of polypropylene/polylactide (PP/PLA) blends. Polymer, 2018, 154, 119-127

56. Ravishankar, P.S.. "Treatise on EPDM". Rubber Chem. Technol. 2012, 85, pp. 327-349. doi:10.5254/rct.12.87993

57. Strapasson, R., Amico, S.C., Pereira, M.F.R., Sydenstricker, T.H.D., Tensile and impact behavior of polypropylene/low density polyethylene blends, Polym. Test., 2005, 24, 468-473

58. Ashby, M.F., Jones, D. R. H., Engineering Materials, Butterworth-Heinemann, 2012, pp 45-104, ISBN 978-0-08-096665-6

59. Brandrup, J., Immergut, E. H., Grulke, E. A., Abe, A., Bloch. Polymer handbook, 1999, pp V-21-V-30 and V-119-V-134.

60. Musteață, A. E., Pelin, G., Botan, M., Deleanu, L., Tensile Tests for Polyamide 6 and Polypropilene, Mechanical Testing and Diagnosis, 2018, 4, 16-22.

61. Brown, R. Handbook of Polymer Testing: Short-Term Mechanical Tests (Rapra Technology Limited), ISBN: 1-85957-324-X, 2002, pp.97126

62. Filippone, G., Dintcheva, N. Tz., Acierno, D., La Mantia, F. P., The role of organoclay in promoting co-continuous morphology in high-density poly(ethylene)/poly (amide) 6 blends. Polymer, 2008, 49, 1312-1322. doi:10.1016/j.polymer.2008.01.045

63. Dupont ${ }^{\mathrm{TM}}$ Zytel ${ }^{\circledR}$ and Minlon ${ }^{\circledR}$ Nylon Resins Molding Guide, Dupont, https://www.dupont.com/content/dam/dupont/amer/us/en/transportation-industrial/public/documents/en/Zytel\%20and\%20Minlon_Nylon_Resin_Molding_Guide_GNE-A11218-00-A1216_050117_OM.PDF

64. Polyamide (Nylon) - Troubleshooting Common Nylon Processing Problems, https://plastics.ulprospector.com/generics/22/c/tr/polyamide-nylon-troubleshooting

65. Li, H., Xu, Y., Zhang, T., Niu, K., Wang, Y., Zhao, Y., Zhang, B., Interfacial adhesion and shear behaviors of aramid fiber/polyamide 6 composites under different thermal treatments, Polym. Test., 2020, 81, 106-209.

66. Ahn, Y-C., Paul, D. R., Rubber toughening of nylon 6 nanocomposites. Polymer, 2006, 47, 2830-2838, doi: 10.1016/j.polymer.2006.02.074.

67. Robeson, L. M., Polymer Blends: A Comprehensive Review, Hanser. Gardner, Munich, Germany, 2007

68. Wang, D., Li Y., Xie X.-M., Guo B.-H., Compatibilization and morphology development of immiscible ternary polymer blends. Polymer, 2011, 52, 191-200.

69. Pawlak, A., Krajenta J., Galeski, A., Cavitation phenomenon and mechanical properties of partially disentangled polypropylene, Polymer, 2018, 151, 15-26

70. Kelnar, I., Khunová, V., Kotek, J., Kaprálková, L., Effect of clay treatment on structure and mechanical behavior of elastomercontaining polyamide\&6 nanocomposite. Polymer, 2007, 48, 5332-5339, doi:10.1016/j.polymer.2007.06.062

71. Shan, G.-F., Yang, W., Yang, M., Xie, B., Feng, J., Fu, Q., Effect of temperature and strain rate on the tensile deformation of polyamide 6. Polymer, 2007, 48. 2958-2968, https://doi.org/10.1016/j.polymer.2007.03.013

72. Milisavljević, J., Petrović, E., Ćirić, I., Mančić, M., Marković, D., Đorđević, M., Tensile testing for different types of polymers, DAS-29, 29th Danubia-Adria Symposium, University of Belgrade, Serbia, 2012, pp 266-269h 